Juan Carlos Morón Urbina*

Universidad San Martín de Porres

Lima, Perú

juancarlos.moron@bakermckensie.com

\title{
Aspectos jurídicos del conflicto de intereses y el buen gobierno ${ }^{* *}$ \\ Juridical aspects of conflict of interests and the good governance
}

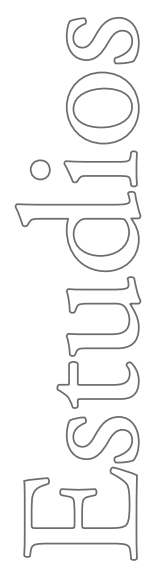

\section{Resumen}

En el presente artículo, el autor se dedica a realizar exhaustivo análisis sobre una institución jurídica de vital importancia para el buen gobierno de las administraciones públicas: la regulación de los conflictos de intereses. En efecto, en sociedades postcapitalistas caracterizadas por una incesante intervención del Estado en la sociedad civil y en el mercado, los efectos de dicho fenómeno han dado paso a una serie de consecuencias negativas, a saber: la captura del regulador, el aumento de la corrupción o la desviación de poder, entre otros síntomas de desgobierno. Así, una vez descrito el panorama institucional y fáctico en el cual surgen los conflictos de interés, el estudio se avoca a reconstruir la categoría de conflicto de interés, especialmente, aquellos que puedan afectar a los servidores públicos, determinado sus elementos configuradores, la extensión o alcance de los conflictos de interés, su tipología, para luego reflexionar sobre las señales que permiten detectarlos, evaluando los medios de control de los conflictos de interés y su eficacia.

*Abogado por la Universidad San Martín de Porres. Maestría en Derecho Constitucional por la Pontificia Universidad Católica del Perú. Directivo de la Asociación Peruana de Derecho Administrativo y miembro del Foro Iberoamericano de Derecho Administrativo. Catedrático de derecho administrativo en la Facultad de Derecho de la Pontificia Universidad Católica del Perú, Universidad ESANy Universidad de Piura.

\section{Palabras clave}

Conflicto de interés - gestión pública - buen gobierno - derechos fundamentales.

\section{Abstract \\ In this article, the author is dedicated to conducting thorough analysis of a legal ins- titution of vital importance for the good governance of public administrations: the regulation of conflicts of interest. Indeed, in post-capitalist societies characterized by an \\ **Artículo recibido el 20 de Octubre de 2014 y aceptado para su publicación el 21 de Abril de 2015.}


incessant intervention in civil society and the market, the effects of this phenomenon have given way to a series of negative consequences, namely: regulatory capture, increased corruption or misuse of powers, among other symptoms of misrule. Thus, once described the institutional and factual scenario in which conflicts of interest arise, the study turns to rebuilding the category of conflict of interest, especially those which may affect public servants, determining its configuring elements, the extension or scope of conflict of interest, their types; and then ponder about the signals that allow to detect them, evaluating the control means of the conflicts of interest and their effectiveness.

Keywords

Conflict of interest - governance - good governance - fundamental rights

Mulier Caesaris non fit suspecta etiam suspicione vacare debet ${ }^{l}$

\section{Planteamiento del tema: La pluralidad de intereses y la necesidad de evitar su concurrencia o superposición en algunas actividades}

Como bien se ha dicho, es conocido que buena parte de los problemas de Ética Pública se resumen con la apelación al llamado conflicto de intereses ${ }^{2}$. Este término es muy acudido en la gestión pública, pero por su complejidad es difícilmente aprendido en su contenido esencial y menos aún en sus contornos o zonas grises. Es cierto. En base a esta figura se han estructurado gran parte de los deberes éticos de los servidores públicos y, a su vez, constituye el fundamento para reprochar diversas figuras vinculadas de una u otra manera con la corrupción, el tráfico de influencias, el nepotismo, el uso indebido de información privilegiada, la concusión y en general, es sinónimo de aprovechamiento de la función pública con fines personales.

Hoy en día no escapa a nuestra conciencia que el conflicto de intereses es aplicado como argumento para reprochar la situación de las empresas auditoras que brindan servicios de consultoría o contabilidad a un mismo cliente, a los médicos cuando recomiendan a sus pacientes medicamentos del laboratorio que le financia una pasantía o cuando refieren el laboratorio de un familiar para realizar un análisis clínico, al contratista de obra cuando promueve un obra adicional que no es necesaria para beneficiarse con

\footnotetext{
La mujer del Cesar no sólo ha de ser honrada sino parecerlo

Rodriguez-Arana Muñoz (1993), p. 69.
} 
ese mayor costo de la obra, al analista económico que valoriza una empresa artificialmente alta porque tiene pensado vender las acciones que posee en esa empresa, y al abogado que asesora una empresa contra otra que también es su cliente. En fin, bien podríamos decir que las situaciones de conflicto de intereses son comunes hoy en día en las organizaciones de todo tipo ${ }^{3}$. En todos estos eventos tenemos una situación de intereses plurales convergentes en un mismo sujeto de derecho. Difiere del tradicional conflicto de intereses abordado por el derecho procesal, en el que el conflicto se produce entre dos o más personas pretendiendo propósitos adversos y excluyentes dentro un mismo proceso, al que podemos denominar "conflictos de intereses intersubjetivos" para diferenciarlos de estos conflictos intrasubjetivos.

Como primera aproximación a este conflicto, hemos advertido que no se trata de una figura exclusiva de la función pública. Por ejemplo, podemos encontrarla en diversas relaciones comunes de derecho privado donde el ordenamiento -atendiendo fundamentos de interés general- regula explícitamente supuestos de conflicto de intereses sin necesidad que haya servicio público ni función pública de por medio. Es el caso de la anulabilidad de acto jurídico celebrado por el representante consigo mismo, salvo que por la forma en que se ha determinado el acto jurídico se hubiera excluido la posibilidad de conflicto de intereses ${ }^{4}$, o la prohibición a determinadas personas para ser tutores, por tener involucrados conflictos de intereses, como son los deudores o acreedores del menor, o quienes posean intereses contrarios a él ${ }^{5}$, la prohibición a los tutores para practicar algunos actos que suponen ese conflicto ${ }^{6} \mathrm{y}$ la de los propios padres para tomar algunas decisiones sobre los bienes de los hijos o asumir deudas en su nombre ${ }^{7}$.

Se afirma que en el ámbito de las organizaciones contemporáneas es posible identificar por lo menos cuatro clases de conflictos: i) Conflictos de intereses interpersonales en el ámbito de la misma empresa (ej. Acoso moral sobre aspectos de personales o de convicciones y acoso sexual); ii) Conflictos intraorganizacionales entre los individuos que laboran y los intereses de las organizaciones para las que trabajan (ej. Conflicto de intereses); iii) conflictos extraorganizacionales: entre la organización y la sociedad o una organización y su entorno (ej. Relaciones con los consumidores, responsabilidad social, conversación del medio ambiente, etc.) y, iv) conflictos interorganizacionales: entre la organización misma y los partícipes con intereses en ella (stakeholders), como son los conflictos de interés con los proveedores, clientes, distribuidores, etc.

4 Artículo 166.- Es anulable el acto jurídico que el representante concluya consigo mismo, en nombre propio o como representante de otro, a menos que la ley lo permita, que el representado lo hubiese autorizado específicamente, o que el contenido del acto jurídico hubiera sido determinado de modo que excluya la posibilidad de un conflicto de intereses.

$5 \quad$ Impedimentos para ejercer tutoría

Artículo 515.- No pueden ser tutores:

3.- Los deudores o acreedores del menor, por cantidades de consideración, ni los fiadores de los primeros, a no ser que los padres los hubiesen nombrado sabiendo esta circunstancia.

4.- Los que tengan en un pleito propio, o de sus ascendientes, descendientes o cónyuge, interés contrario al del menor, a menos que con conocimiento de ello hubiesen sido nombrados por los padres.

5.- Los enemigos del menor o de sus ascendientes o hermanos.

6 Artículo 538.- Se prohíbe a los tutores:

1.- Comprar o tomar en arrendamiento los bienes del menor.

Artículo 447.- Prohibición de los padres de enajenar y gravar bienes del hijo

Los padres no pueden enajenar ni gravar los bienes de los hijos, ni contraer en nombre de ellos obligaciones que excedan de los límites de la administración, salvo por causas justificadas de necesidad o utilidad y previa autorización judicial. El juez puede disponer, en su caso, que la venta se haga previa tasación y en pública subasta, cuando lo requieran los intereses del hijo. 
Incluso la necesidad de acudir a un curador especial cuando los intereses de los hijos se encuentren en contraposición a los de los padres que ejercen patria potestad al igual que cuando se encuentren en similar situación los intereses de los tutores o curadores ${ }^{8}$.

Incluso en las relaciones societarias comerciales son contempladas regulaciones específicas en caso surjan conflictos de intereses entre los accionistas y los intereses de la sociedad así como entre los intereses de los gerentes y el de los accionistas ${ }^{9}$, señalándose, por ejemplo, la suspensión del derecho a voto de los accionistas en conflicto con la sociedad ${ }^{10}$ y que los directores no pueden adoptar acuerdos que cautelen sus propios intereses o los de terceros relacionados, ni usar en beneficio propio las oportunidades comerciales o de negocios de que tuvieren conocimiento en razón de su cargo, ni participar por cuenta propia o de terceros en actividades que compitan con la sociedad, sin el consentimiento expreso de ésta ${ }^{11}$.

En todas estas situaciones, indistintamente en el ámbito de las relaciones privadas o públicas, los ordenamientos brindan diversos tratamientos jurídicos para prevenir y regular la coexistencia o superposición de intereses (representantes, tutores, curadores, padres, gerentes, accionistas, etc.) en una misma persona por las lealtades que esos roles demandan y son incompatibles con sus propios y naturales intereses. Nos encontramos así con los conflictos de intereses que la ética describe como aquella situación en la que

“(...) un interés interfiere o puede interferir con la capacidad de una persona, organización o institución para actuar de acuerdo con el interés de otra parte, siempre que aquella persona, organización

8 Artículo 606.- Supuestos en que se requiere curador especial

Se nombrará curador especial cuando:

1.- Los intereses de los hijos estén en oposición a los de sus padres que ejerzan la patria potestad.

4.- Los intereses de los sujetos a tutela o a curatela estén en oposición a los de sus tutores o curadores, o a los de otros menores o incapaces que con ellos se hallen bajo un tutor o curador común.

$9 \quad$ Ley General de Sociedades, Ley No 26887

Artículo 180.- Conflicto de intereses

Los directores no pueden adoptar acuerdos que no cautelen el interés social sino sus propios intereses o los de terceros relacionados, ni usar en beneficio propio o de terceros relacionados las oportunidades comerciales o de negocios de que tuvieren conocimiento en razón de su cargo. No pueden participar por cuenta propia o de terceros en actividades que compitan con la sociedad, sin el consentimiento expreso de ésta.

El director que en cualquier asunto tenga interés en contrario al de la sociedad debe manifestarlo y abstenerse de participar en la deliberación y resolución concerniente a dicho asunto.

El director que contravenga las disposiciones de este artículo es responsable de los dańos y perjuicios que cause a la sociedad y puede ser removido por el directorio o por la junta general a propuesta de cualquier accionista o director.

10 Ley General de Sociedades, Ley No 26887

Artículo 133.- Suspensión del derecho de voto

El derecho de voto no puede ser ejercido por quien tenga, por cuenta propia o de tercero, interés en conflicto con el de la sociedad.

En este caso, las acciones respecto de las cuales no puede ejercitarse el derecho de voto son computables para establecer el quórum de la junta general e incomputables para establecer las mayorías en las votaciones.

El acuerdo adoptado sin observar lo dispuesto en el primer párrafo de este artículo es impugnable a tenor del artículo 139 y los accionistas que votaron no obstante dicha prohibición responden solidariamente por los daños y perjuicios cuando no se hubiera logrado la mayoría sin su voto.

11 Así podríamos seguir con diversas profesiones y actividades comerciales como médicos, abogados, ingenieros, periodistas, etc. 
o institución tenga la obligación (legal, convencional fiduciaria o ética) de actuar de acuerdo con el interés de la otra parte" ${ }^{12}$.

Los casos enumerados, nos advierten que la aparición de un conflicto de intereses necesita la concurrencia de seis elementos, tal como han sido descritos por la ética normativa:

- Una persona, organización o institución (agente) en la cual concurran dos lealtades distintas y que se implican recíprocamente en la adopción de decisiones.

- Existencia de una relación en la que se valora como indispensable la obligación legal, contractual, convencional, profesional o fiduciaria de actuar conforme con los intereses de otro sujeto principal (persona, organización o institución) y no del propio. En todos estos casos, resulta exigible al sujeto un deber de lealtad con los intereses del otro y a la vez, la obligación de conducirse en su actividad de manera que inspire y acreciente la confianza de ese otro, cuyo interés resulta principal en esta relación. Las relaciones que existen entre padres e hijos, representantes y representado, tutor y tutelado, curador y quien es objeto de la curatela, medico con el paciente, auditor con la credibilidad publica, del accionista con los intereses de la sociedad, de los gerentes de la empresa con los intereses de la sociedad que le son confiados, son muestra precisamente de ello: confianza en la base y en el desarrollo que debe ser honrada permanentemente a través del ejercicio leal de las facultades otorgadas legal o convencionalmente. En ese contexto el máximo gesto de deslealtad aprovecharse de aquellas, para tornarlas en beneficio personal. En suma, la especial situación del principal queda caracterizada por demandar al sujeto medidas de altruismo, entendido como la diligencia en procurar el bien ajeno aun a costa del propio.

- Coexistencia en el sujeto de otro interés (económico, profesional, corporativo, amical, partidaria) que también -bajo otras condiciones- desearía promover o no dificultar.

- Que ese otro Interés, sea propio o ajeno, pero atribuible a él por su relación personal (parientes, amigos, comunidades o colectivos a los que pertenece, empresas, sindicato, partido político, etc.)

- Una incompatibilidad total o parcial de ese interés que le es atribuible con el interés del principal (ej. Curado, tutelado, interés de la sociedad, del representado, etc.)

- De modo que se imposibilita, dificulta o puede dificultar o se teme que imposibilite o dificulte, el cumplimiento del principal deber legal, convencional o profesional por parte de ese sujeto hacia el principal.

12 Argandoña (2004). 
En esta línea de pensamiento, la perspectiva de la ética mayoritaria ${ }^{13}$, de orden altruista, opuesta a la vertiente utilitaria o individualista, afirma que la noción de conflicto de intereses nos plantea necesariamente las siguientes valoraciones desde la perspectiva del debe ser:

- No es correcto actuar contra los intereses del principal en el conflicto de intereses, porque precisamente el sujeto en esta situación tiene la obligación de actuar preferentemente de acuerdo con el interés del principal y no del propio.

- No es correcto ni aceptable obtener o dar la apariencia de obtener un beneficio indebido, económico o de otro tipo, en el desempeño de una profesión, cargo o función.

- Los conflictos de intereses son igualmente reprochables aun cuando el agente no sea culpable de encontrarse en esa situación. Es una situación que suele producirse por la pluralidad de intereses existentes y por el desarrollo de la individualidad de las personas. Es un evento inevitable que se presenta ocasionalmente en el ejercicio de actividades confiadas por terceros, por lo que se hace necesario una prevención y un procesamiento, sin necesidad de aparejar, necesariamente en todos los casos, un juicio de culpabilidad personal hacia el sujeto en conflicto.

- Encontrarse en una situación de conflicto de intereses no es algo en si inmoral, si no se es responsable de ello. Su acaecimiento puede derivarse de hechos de terceros o incluso por eventos ajenos a la voluntad del sujeto, pero también puede provenir de acciones deliberadas del actor, en cuyo caso, si sería reprochablemente personalmente.

- Es éticamente incorrecto ponerse voluntariamente en una situación en que pueda surgir un conflicto de intereses.

- Por tanto, cuando el sujeto se encuentra a cargo del rol de cuidado de situaciones de terceros debe evitar no solo el conflicto de intereses de facto, sino también su apariencia, porque la integridad en la tarea encomendada, la confianza y el respeto de terceros hacia su función son bienes por sí mismos valiosos y dignos de protección. Cuando un sujeto se encuentra en conflicto de intereses, incluso cuando se toman las decisiones correctas, pueden ser tan dañinos para la reputación y confianza de la relación como si se produjera el aprovechamiento mismo.

13 Existe otra doctrina filosófica, denominada del "Egoísmo moral o ético" que afirma que las personas por su desarrollo personal y afirmación de sí mismo, deben tener la normativa ética de obrar en su propio interés porque es la única y natural forma moral de obrar, y las acciones en favor del interés de otro (altruismo), corresponde cuando esa acción proporcione también un beneficio propio. La crítica que se hace al egoísmo ético es que valora interesadamente el altruismo, porque no le da ningún valor a los intereses ajenos por sí mismo: cuando conviene se respetan, pero a veces conviene no respetarlos. En consecuencia, para el egoísmo ético los conflictos de intereses entre el subordinado y el principal se resolverías más bien actuando siempre conforme al interés personal y, ello implica que podría sacrificarse el interés propio en el corto plazo para maximizar el interés propio a largo plazo. En esa línea tenemos los estudios de Olson, Robert G; "The morality of self-interest", Henry Sidgwick; The Methods of Ethics. London, 1874; James Rachels; The Elements of Moral Philosophy", 
- En una situación de conflicto potencial de intereses existe, una graduación de valoraciones éticas, en función de la probabilidad de incurrir realmente una situación de conflicto, de la importancia del daño que se pueda causar y de la relevancia del interés personal que se enfrente al del principal. Pero en todos los casos, debe evitarse aun la situación de potencial conflicto.

- Los involucrados y responsables de esa función de cautela de situaciones de terceros deben permanentemente atentos para asumir su responsabilidad en la identificación, prevención y resolución de los conflictos de intereses.

\section{II. ¿Por qué se regulan los conflictos de intereses de servidores públicos?}

La ilusa confianza con que Max Weber ${ }^{14}$ idealizó a la burocracia institucional parecería excluir la existencia de algún conflicto de interés en los servidores públicos. Conforme a su planteamiento, la burocracia institucional aseguraba el ejercicio de las funciones públicas y la resolución de los más variados aspectos de interés público siempre de manera objetiva, conforme a normas calculables y sin tomar en cuenta a las personas. En eso radicaba en gran medida la tesis: una ilusión que la realidad contemporánea se encarga de revelarnos como tal.

Para Max Weber, “(...) solo la burocratización del Estado, y de la ley en general, brinda una posibilidad determinada de diferenciar drástica y conceptualmente un orden objetivo de los derechos subjetivos del individuo garantizados por aquel: separar el derecho público del derecho privado" y sobre todo alcanzar "la despersonalización más completa posible de la dirección administrativa por parte de la burocracia"15.

Lamentablemente la realidad nos reveló que si bien la burocracia institucional supuso un estado superior respecto al estado patrimonialista anterior, no puede asegurar por sí mismo, que los servidores dejen de atender sus fines personales al adoptar decisiones públicas. Es más, todo servidor público tiene intereses personales y también a su cargo la defensa del interés general, pero debe mantenerlos suficientemente disgregados. El ejercicio de la función pública exige la delimitación clara entre los diversos fines que tiene una persona con un cargo público: los fines privados (personales y a los grupos que pertenece, en sus vertientes económica, familiar, amical, entre otros), los fines del partido o agrupación política a la que se pertenece y los fines del Estado, de la colectividad como tal, que se denomina interés público o búsqueda del bien común.

Como afirma Savater, la ética de la función pública exige tener bien claros los tres fines, “(...) los tres son legítimos, pero lo sin mientras no se mezclen; es decir, una persona, un político no puede tomar determinadas

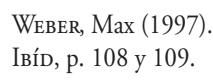


decisiones que le benefician a él personalmente, o a su partido, con el pretexto de que benefician a la colectividad. Lo importante es que se distingan esos fines, que el político sepa diferenciar la actividad con unos fines o con otros. Y si uno no es capaz de distinguir entre los diversos fines, no debe ofrecerse para la actividad pública, pues es obvio que esa persona no puede ocupar un lugar público, ni tampoco lo puede hacer una persona fanatizada y obsesionada con su propio partido, de tal manera que realmente sea incapaz de ver que la sociedad es un todo" ${ }^{16}$.

El servidor debe distinguir y separar radicalmente los intereses personales del interés público a su cargo, adoptando todas las medidas a su alcance para prevenir o evitar su conjunción real, aparente o potencial, en el desempeño de su actividad que menoscabe la credibilidad en la recta gestión pública. Si eso no es logrado de modo espontáneo mediante el autocontrol y la disciplina funcional, el ordenamiento jurídico administrativo está llamado a incluir los instrumentos necesarios de reforzamiento para dicho objetivo. De lo contrario, se pierde la legitimidad democrática del sistema político al ponerse en tela de juicio la apariencia de imparcialidad que debe resguardar la Administración Publica. Como se ha manifestado, "existe un razonable consenso que la falta de control y prevención de las situaciones de conflictos de interés afecta la calidad del sistema político y de la democracia. Las situaciones de conflicto de interés generan un paulatino descreimiento de la población en la legitimidad de las decisiones públicas" 17 .

Como en los casos analizados en el derecho privado, el conflicto de interés tiene lugar en aquellas relaciones en las que una persona tiene el deber de actuar conforme a los intereses de otra, vinculándola a ambas básicamente por confianza y lealtad. Eso es precisamente lo que sucede entre la ciudadanía y los servidores públicos. La diferencia está en que mientras que en el derecho común la relación de confianza y lealtad es entre privados, aquí es entre quienes detentan temporalmente el poder público y sus titulares permanentes, poniendo en cuestión la relación de confianza pública base de estado de derecho. Pero el diagnóstico es más grave en el caso del servicio público porque las situaciones de conflicto intereses conducen potencialmente a distintas situaciones reprochables para la gestión pública: Desde la captura del estado por intereses privados, la institucionalización de la puerta giratoria en el acceso y salida de servidores. Incluso las situaciones de conflicto de interés no prevenidas, trasparentadas o resueltas a tiempo, pueden derivar en daños a la gestión de las entidades, al patrimonio público a través de actos de corrupción. Es precisamente esto último sobre el cual cabe llamar la atención, por cuando el conflicto de interés está vinculado estrechamente con la corrupción, dado que es la base y fuente de muchas prácticas tipificadas como corruptas aun cuando no tienen que acabar necesariamente en una conducta reprochable penalmente. 
Para la gestión pública, la noción de conflicto de interés se sustenta en tres deberes funcionales inherentes al servicio público ideal ${ }^{18}$, por lo que aun careciendo de una definición legal en los ordenamientos, igualmente seria reprochable este conflicto:

- Los servidores públicos no deben hacer mal uso o abusar del cargo público para obtener beneficios o ganancias adicionales a las previstas como compensación para sí mismo o para terceros ${ }^{19}$.

- Los servidores públicos deben anteponer el bienestar del público a sus intereses privados, o como establece el ordenamiento nacional, o ser desinteresados ya que por ocupar cargos públicos deben tomar decisiones sólo con arreglo al interés público ${ }^{20}$. Como plantea el ordenamiento nacional "es obligación de los servidores civiles privilegiar los intereses del Estado sobre los intereses propios o de particulares"21.

- Los servidores públicos deben cumplir con sus obligaciones con imparcialidad y neutralidad política, económica y de cualquier índole, demostrando independencia frente a sus vinculaciones con personas, partidos políticos, grupo o instituciones ${ }^{22}$.

Particularmente, la preocupación contemporánea por abordar el conflicto de intereses directamente se ha centrado en torno a determinados procesos claves de la acción gubernamental contemporánea: adquisiciones y contrataciones, asociaciones público privadas, proyectos de infraestructura, relaciones con personas jurídicas o privadas en actividades de ordenación (permisos, autorizaciones, etc.), prestación (subsidios, estímulos o apoyos económicos), y regulación económica en diversos sectores.

\section{III. ¿Qué es conflicto de intereses?}

El conflicto de interés está en la base de innumerables reglas jurídicas, como el deber de abstención, algunas causales de nulidad de acto, y no pocas prohibiciones e incompatibilidades impuestas al servicio civil, tales como uso de información obtenida en el cargo público, aceptar empleo de empresas sobre las cuales ha recaído su gestión pública, ejercer su profesión o actividad privada respecto de algunos temas o materias, incurrir en nepotismo, participar en asunto en que participen familiares o amistades, representar intereses de particulares ante su propia entidad. Digamos que todas estas

\footnotetext{
RaILE.

Art. 157 literal c), D.S: No. 040-2014-PCM.

El Informe Nolan consigna como uno de los siete principios de la Vida Pública al Desinterés, entendiéndolo que "Los que ocupan cargos públicos deberían tomar decisiones sólo con arreglo al interés público". "Normas de Conducta para la Vida Pública. El Informe Nolan” Serie Documentos INAP, Ministerio de Administraciones Públicas, Instituto Nacional de Administración Pública.

21 Art. 39 literal b), Ley No. 30057, del Servicio Civil.

22 Art. 39 literal g), Ley No. 30057, del Servicio Civil. Y art. 156 literal b) del D.S. No. 040-2014, Reglamento General de la Ley No. 30057.
} 
regulaciones, presuponen la noción del conflicto de intereses, por lo que es recomendable, contar con una definición aplicable a los casos del servicio público.

\section{Aproximación a una definición.}

Los instrumentos internacionales en materia de corrupción presuponen la noción de conflicto de interés, pero no alcanzan consenso alrededor de una definición unitaria. NI la Convención Interamericana contra la Corrupción de 1996, la Convención para Combatir el Cohecho de Servidores Públicos Extranjeros en Transacciones Comerciales Internacionales de la Organización para la Cooperación y Desarrollo Económicos (OCDE) adoptada en 1997, ni la Convención de las Naciones Unidas Contra la Corrupción de 2003, contienen definición concreta de lo que debemos entender por conflicto de intereses, aunque claramente lo identifican como un evento reprobable y que debe evitarse como una forma eficiente de prevenir la corrupción.

Los documentos de la OCDE nos proporcionan algunas aproximaciones importantes cuando afirman que:

"El conflicto de intereses de los responsables públicos es un conflicto entre obligaciones públicas e interés privado que puede indebidamente influir en el cumplimiento de sus obligaciones y responsabilidades" 23 .

Por otro lado, otro de sus documentos, alcanzan otra definición partiendo del interés privado que influye en la imparcialidad de la gestión pública:

"un conflicto de intereses nace de una situación en la que un agente público tiene un interés personal que influya o aparente influir sobre el ejercicio imparcial y objetivo de sus funciones públicas" ${ }^{24}$.

Por su lado, los ordenamientos nacionales tampoco han sido muy pródigos en aportar alguna definición de conflicto de interés. Sin embargo, hemos podido identificar definiciones interesantes, como las siguientes:

"conflicto de interés: aquella situación en la que el interés personal o económico está o puede razonablemente estar en pugna con el interés público" 25 .

"A fin de preservar la independencia de criterio y el principio de equidad, el funcionario público no puede mantener relaciones ni aceptar situaciones en cuyo contexto sus intereses personales, laborales, económicos o financieros pudieran estar en conflicto con el

23 OCDE (2004).

24 Art. 13.1. "Código Modelo de Conducta para los agentes públicos", Recomendación No. R (2000) 10, aprobada por el Consejo de Ministros del Consejo de Europa.

25 Ley No. 01 -2012, Ley de Ética Gubernamental del Puerto Rico de 2011, Articulo 1.2. Definiciones. 
cumplimiento de los deberes y funciones a su cargo"26.

“Artículo 40. Conflicto de intereses. Todo servidor público deberá declararse impedido para actuar en un asunto cuando tenga interés particular y directo en su regulación, gestión, control o decisión, o lo tuviere su cónyuge, compañero o compañera permanente, o algunos de sus parientes dentro del cuarto grado de consanguinidad, segundo de afinidad o primero civil, o su socio o socios de hecho o de derecho.

Cuando el interés general, propio de la función pública, entre en conflicto con un interés particular y directo del servidor público deberá declararse impedido" 27 .

"Artículo 4 Objeto

1. A los efectos de esta ley, hay conflicto de intereses cuando los altos cargos intervienen en las decisiones relacionadas con asuntos en los que confluyen a la vez intereses de su puesto público e intereses privados propios, de familiares directos, o intereses compartidos con terceras personas.

2. El presente título regula la prevención y resolución de conflictos de intereses a través del establecimiento de un régimen de incompatibilidades y de las correspondientes sanciones ${ }^{28}$.

Si bien todas tienen aparentemente cercanos contenidos, podríamos hacernos algunas preguntas a partir de sus textos. ¿Para su configuración basta la capacidad de influir del interés privado?, o por el contrario es necesario que influya efectivamente?, ¡cabe hablar de una Influencia potencial? ¿Es necesario para su existencia, de dolo del sujeto, o que éste alcance algún beneficio?

2. El elemento subjetivo indispensable para determinar el alcance del conflicto de interés en la función pública

Antes hemos abordado la situación del conflicto de intereses y sus elementos desde la óptica de la ética en general. Ahora nos corresponde agregar un elemento determinante para distinguir con propiedad su alcance.

Recordemos que en la base de todo conflicto de interés debe existir una persona, denominada agente, en la cual concurran dos lealtades distintas y excluyentes en la

\footnotetext{
Código de Ética de la Función Pública, Decreto No. 41/99. Argentina.

Código Disciplinario Único, Colombia.

Ley 5/2006, de 10 de abril, de regulación de los conflictos de intereses de los miembros del Gobierno y de los Altos Cargos de la Administración General del Estado.
} 
adopción de decisiones. La primera lealtad que sirve de fundamento al conflicto, es la relación legal y contractual en la cual se encuentra el agente por la cual le es exigible actuar conforme con el interés general, privilegiándolo frente al propio, y la obligación de conducirse en su actividad de manera que inspire y acreciente la confianza de ese otro, cuyo interés resulta principal en esta relación.

En nuestro caso resulta evidente que esa persona, llamada hasta el momento de manera general como agente, es el servidor público, en cualquiera de sus manifestaciones, comprendiendo al servidor de confianza, directivo o en cargo político, incorporado a la carrera pública o incluso, si fuera sujeto a una relación contractual eventual de trabajo. Lo importante es que desempeñe una función pública a partir esa labor o cargo que le ha sido confiada. Este servidor público tiene el deber de fiduciario respecto a la colectividad en general que ha confiado sus intereses a sus decisiones y actividades. En esta línea se inserta la definición incluida en nuestro Código de Ética de la Función Pública

“4.1 Para los efectos del presente Código se considera como empleado público a todo funcionario o servidor de las entidades de la Administración Pública en cualquiera de los niveles jerárquicos sea éste nombrado, contratado, designado, de confianza o electo que desempeñe actividades o funciones en nombre del servicio del Estado".

4.2 Para tal efecto, no importa el régimen jurídico de la entidad en la que se preste servicios ni el régimen laboral o de contratación al que esté sujeto. ${ }^{29}$

El interés privado concurrente en el empleado y que resulta superpuesto en el caso concreto puede ser propio o ajeno, pero la relación estrecha que se tiene con ese otro titular, les resulta imputable al empleado. Este último caso, serían los intereses propios de sus familiares directos, conviviente, de la empresa en la cual tiene acciones, del partido político al cual pertenece y cualquier persona jurídica integrada o dirigida por el empleado, entre otros. De este modo, el conflicto se estructura no sólo por configurarse alguno de los supuestos de hecho respecto del servidor, sino también respecto de sus allegados.

En cuanto al contenido ese otro interés puede ser de orden laboral, económico, social, financiero, amical, político, etc., pero en todos los casos, debe ser evitado o excluido. Equivocadamente se plantea que el interés privado para calificar de conflicto debe centrarse únicamente en los intereses de carácter financiero o económico , es decir, aquellos que enfrentan al cargo o funcionario público ante el dilema de beneficiar su interés pecuniario o económico personal o favorecer el interés general, por más que ambos puedan verse más de una vez entrelazados. Pero ello no resulta de recibo. Nuestra Ley del Código de Ética de la Función Pública califica ello de la siguiente manera:

29 Ley del Código de Ética de la Función Pública aprobado por Ley No 27815, modificado por Ley № 28496 


\section{Artículo 8.- Prohibiciones Éticas de la Función Pública}

El servidor público está prohibido de:

\section{Mantener Intereses de Conflicto}

Mantener relaciones o de aceptar situaciones en cuyo contexto sus intereses personales, laborales, económicos o financieros pudieran estar en conflicto con el cumplimento de los deberes y funciones a su cargo.

Hasta aquí queda confirmado que el deber de altruismo y la prohibición de incurrir en conflicto de intereses es inherente a quienes ejercen - bajo cualquier título- la función pública y por ende, califican como servidores públicos.

\section{La extensión del alcance del conflicto de interés a algunos colaboradores de la administración}

No obstante el alcance no estaría completo si dejamos de analizar las particularidades que presentan ciertas técnicas de asociación de sujetos privados a la realización de función pública permitiendo la extensión de los conflictos de intereses a sujetos que no son cabalmente servidores públicos. Nos referimos concretamente a los sujetos privados incorporados a órganos colegiados representativos, al ejercicio privado de ciertas públicas (ej. Concesionarios), y a la colaboración con la función pública por parte de algunos contratistas (ej. Supervisores o auditores). En todos ellos, sin ser propiamente servidores públicos, de una u otra manera, las normas suelen extender, en tanto mantengan la condición de tales, el deber de privilegiar el interés público y la prohibición en incurrir en conflicto de intereses.

Algunas veces el esquema jurídico permite la incorporación de sujetos privados a organismos administrativos colegiados decisorios, consultivos o de control planteando una modalidad de participación en la gestión pública ${ }^{30}$. Como es evidente, la participación en estos organismos — que por tal condición se les llama representativos ${ }^{31}$ — está basada en la búsqueda de alcanzar la representación más directa de intereses de grupos sociales no estatales, como suelen ser: Gremios, empresariado, consumidores, usuarios, ecologistas, expertos técnicos o profesionales representando a colegios profesionales. La participación de los administrados en algunos órganos administrativos junto al personal al servicio de las Administraciones públicas en representación de intereses diversos es una fórmula extendida en nuestra legislación en sectores como el educativo, la sanidad, aguas, seguridad social, universidades, entre

30 Respecto a este tema pueden leerse con provecho: Carbonell Porras (1999), p. 45 y ss. Sainz Moreno (1983), p. 1699 y ss.

31 No nos referimos a los casos en que el ordenamiento permite a organismos de la sociedad civil o colegios profesionales designar integrantes a órganos colegiados del Estado pero sin representación, como sucede con el Consejo de la Magistratura. 
otros, y encuentran una regulación general en el artículo 95 de la Ley de Procedimiento Administrativo General cuando afirma que quedan sujetas a su regulación los casos de órganos colegiados, "incluidos aquellos en los que participen representantes de organizaciones gremiales, sociales o económicas no estatales".

Precisamente los representantes incorporados a estos organismos administrativos poseen intereses colectivos propios que se quiere tengan presencia en su toma de decisiones para conformar el interés público a seguir. Ello conlleva indefectiblemente a enfrentamiento de intereses en los órganos integrados por representantes de la administración o de otros representantes de intereses privados, pero consideramos que ello no califica como conflictos de intereses en los términos que venimos estudiando.

La pregunta es si los representantes del sector privado por ejercer estos cargos alineando sus decisiones u orientaciones al interés corporativo que justamente representa, se puede incurrir en conflicto de intereses. En nuestra opinión no, aquí existe, en algunos casos, probablemente intereses en conflicto, entre esa representación privada y el interés público que es llamado a ser tutelado por la administración. Pero ello es así, precisamente porque el esquema precisamente pretende que en la conformación del interés público en cada decisión participen directamente representantes de ese interés privado vinculado a la gestión al interior de los órganos colegiados. Distinto sería si ese representante, en vez de atender el interés privado al que representa, pretendiera beneficiarse personalmente con la toma de decisiones.

Un supuesto distinto pero en el que también es usual extender los conflictos de intereses es a algunos contratistas del Estado atendiendo a las prestaciones que ejecuta a las entidades realizara. Es el caso emblemático de los servicios de auditoria contratados por las entidades de la Administración Pública cuyos contratistas -al igual que en sector privado- necesitan resguardar la independencia de sus opiniones y el deber de privilegiar el interés público antes que el propio. Para ello, el ordenamiento administrativo establece, por ejemplo, que no pueden prestar servicios de auditoría a las entidades si las empresas, sus socios y/o personal profesional tienen o han mantenido vínculo laboral o contractual (cualquiera sea su objeto), bajo cualquier forma o modalidad, con la Entidad a examinar o con los titulares, representantes legales o funcionarios 
de ésta, dentro del año anterior al período por auditar, incluyendo al período sujeto a examen, entre otros supuestos ${ }^{32} 33$.

De igual manera se extienden los conflictos de interés a los contratistas del estado según se trata de tener relaciones con servidores públicos o por los propios servicios que ha prestado a las entidades con anterioridad. Por ejemplo, se encontrara impedido de ser postor o contratista del Estado aquella empresa en la que participen accionistas funcionarios y servidores públicos de las entidades que convocan el proceso así como aquellas que con anterioridad prestaron servicios a la propia entidad participando directamente en la determinación de las características técnicas y valor referencial, elaboración de Bases, selección y evaluación de ofertas de un proceso de selección y en la autorización de pagos de los contratos derivados de dicho proceso ${ }^{34}$.

\section{El conflicto entre intereses públicos en la propia gestión}

Como ha quedado manifestado, el conflicto implica la concurrencia de un interés privado en quien ejerce la función pública. Hasta donde hemos advertido ese interés a evitarse o desestimarse puede ser de orden material, económico, financiero, laboral, amical u otros. Suceden, sin embargo, situaciones análogas cuando ese otro interés personal también se haya en relación con el desempeño de otras actividades en la organización administrativa y no en ámbito privado. Pensemos en el servidor a cargo de supervisar, controlar o aprobar los actos funcionales ha realizado el mismo o alguien vinculado estrechamente a él.

32 El Reglamento de las Sociedades de Auditoria conformantes del Sistema Nacional de Control se establece lo siguiente:

Articulo 30.-Impedimentos

Las Sociedades están impedidas de participar en el Concurso, ser designadas, y/o realizar labores de auditoría en los casos siguientes:

a) Si las Sociedades, sus socios y/o personal profesional propuesto como integrante de) equipo tienen o han mantenido vínculo laboral o contractual (cualquiera sea su objeto), bajo cualquier forma o modalidad, con la Entidad a examinar o con los titulares; representantes legales o funcionarios de ésta, dentro del año anterior al período por auditar, incluyendo al período sujeto a examen.

b) Si sus socios y/o personal profesional propuesto como integrante del equipo tienen relación de parentesco dentro del cuarto grado de consanguinidad y segundo grado de afinidad con el titular, directivos o funcionarios de la Entidad, incluyendo los del período bajo examen.

(...)

l) Si las Sociedades, sus socios V/o personal profesional propuesto tienen razones objetivas que los hagan pasibles de incurrir en otras causales de incompatibilidad o conflicto de intereses respecto a la Entidad, su titular, directivos y funcionarios, incluyendo los del período a auditar.

33 Esta extensión se concreta también en las empresas privadas que son contratadas por los organismos reguladores para comprobar el cumplimiento de los deberes legales y contractuales de los concesionarios. Véase el Reglamento para la Contratación de Empresas Supervisoras por parte de OSITRAN, aprobada por Decreto Supremo No 035 2001-PCM y su Texto Único Ordenado de las Disposiciones Complementarias al Reglamento de Contratación de Empresas Supervisoras, aprobado por Decreto Supremo No 035-2001-PCM

34 Ley de Contrataciones del Estado, articulo 10. 
Es claro que aquí no hay ningún interés proveniente de actividades privadas del servidor, pero resulta obvio que existirá conflicto entre el interés de analizar objetivamente la decisión sujeta a su control y el interés en que aquel proyecto o decisión sea encontrada regular y aprobada finalmente. Este supuesto es explícitamente previsto para el caso del personal que está a cargo de ejercer el control gubernamental sobre los actos y decisiones de las demás entidades públicas, por lo que se aplican una serie de impedimentos o prohibiciones en esa línea. Por ejemplo, no pueden ejercer esta actividad pública si se tiene vínculo de parentesco dentro del cuarto grado de consanguinidad y segundo de afinidad, con quienes realicen funciones de dirección en la entidad, con los que tienen a su cargo la administración de bienes o recursos públicos, aun cuando éstos hayan cesado en sus funciones; o si han desempeñado en la entidad actividades de gestión en funciones ejecutivas o de asesoría ${ }^{35}$.

Otro caso semejante es el de los regidores de los Concejos Municipales que siendo los legisladores y fiscalizadores de la organización municipal incurrirían en conflicto de interés concurrente si se le permitieran participar en la administración activa de la misma corporación. Por ello, no pueden ejercer funciones ni cargos ejecutivos o administrativos, ni ocupar cargos de miembros de directorio, gerente u otro, en la misma municipalidad o en las empresas municipales o de nivel municipal de su jurisdicción, siendo causal de nulidad de sus actos y vacancia para quien incurra en este conflicto de interés ${ }^{36}$.

\section{El conflicto de intereses tolerado en la gestión pública}

Es conveniente tener en cuenta que cualquier regulación de conflicto de intereses debe atender -como cualquier regla jurídica- a una justificación razonable. Ello implica que las medidas restrictivas que implica deba ser adecuadas para lograr el fin constitucionalmente válido de probidad administrativa; necesarios, es decir, que las restricciones, prohibiciones e impedimentos se apliquen solo cuando no exista un medio

35 Resolución de Contraloria No 459-2008-Cg; "Reglamento De Los Órganos De Control Institucional" Artículo 11.- Personal del OCI.-

Los OCI deberán estar conformados por personal multidisciplinario seleccionado en relación con los objetivos y actividades que realiza la entidad. Son requisitos mínimos que debe cumplir el personal conformante del OCI, d) No tener vínculo de parentesco dentro del cuarto grado de consanguinidad y segundo de afinidad, o por razón de matrimonio, con quienes realicen funciones de dirección en la entidad, así como, con aquellos que tienen a su cargo la administración de bienes o recursos públicos, aun cuando éstos hayan cesado en sus funciones en los últimos dos (02) años (Declaración Jurada).

Artículo 25.- Requisitos para asumir el cargo de Jefe del OCI

Para asumir el cargo de Jefe de OCI, cualesquiera sea la forma de designación, se deben cumplir los siguientes requisitos:

h) No tener vínculo de parentesco dentro del cuarto grado de consanguinidad y segundo de afinidad, o por razón de matrimonio, con funcionarios y directivos de la entidad o con aquellos que tienen a su cargo la administración de bienes o recursos públicos, aun cuando éstos hayan cesado en sus funciones en los últimos dos (02) años i) No haber desempeñado en la entidad actividades de gestión en funciones ejecutivas o de asesoría en los últimos cuatro (04) ańos.

36 Ley Orgánica de Municipalidades (Ley No. 27972), Articulo 11. 
menos oneroso para alcanzar el fin, como pueden ser la declaraciones de conflicto, o la responsabilidad funcional por su transgresión; y que sean proporcionales, esto es, que las restricciones no sacrifique otros valores y principios que tengan respaldo constitucional también.

En este contexto, la regulación restrictiva que los conflictos de interés suponen es puesta en cuestión desde la perspectiva de su razonabilidad cuando una excesiva rigurosidad en su aplicación puede llevar a impedir, dificultad o privar a la propia administración captar o mantener personal competente y especializado para alguna posición en la gestión pública. Así, se evita una reducción irrazonable de potenciales servidores públicos o incluso la imposibilidad de captar personal para la gestión pública. Por ejemplo, seria desproporcionado si se considera establecer la prohibición a los servidores a cargo de la función de supervisor de bancos mantener cuentas bancarias o tomar un préstamo en una empresa financiera del Sector, o al servidor a cargo de la regulación eléctrica, impedirle tener un contrato de suministro eléctrico con una empresa concesionaria que a su vez es regulada. En estos casos, los intereses privados del servidor con la empresa financiera o la concesionaria de electricidad no corresponde a un aprovechamiento o ventaja sino a una condición necesaria para la vida social ordinaria común para la generalidad de ciudadanos.

En ambos, la legislación se inclina por la tolerancia del conflicto, sin perjuicio de aplicar mecanismos alternativos de transparencia, como declaraciones, rotación de funciones, abstención, entre otros, para su prevención y revelación pública.

\section{Una posible definición de conflicto de interés para la gestión pública}

En ese contexto, podemos definir al conflicto de intereses como una situación o estado de $\operatorname{cosas}^{37}$ de riesgo objetivamente razonable para el interés público confiado a un servidor, que surge porque él mismo admite o mantiene, a la vez, legítimos intereses personales de origen privado (familiares, amicales, económicos, sociales, partidarios) que pueden dar efectivamente o aparentar que existirá influencia o incentivo para favorecerlos en desmedro o por encima del interés público (desvío de poder) o cuando menos, afectaría la objetividad del criterio para adoptar la decisión que le compete.

Así, la noción de conflicto de intereses caracteriza una situación en la que las personas participantes en la decisión gubernativa tienen obligaciones profesionales, personales, intereses personales o económicos contrapuestos que podrían hacer que les resultase

37 Con acierto se dice que "Con respecto a los conflictos de intereses, (...) no se trata de una conducta sino de una situación o estado de cosas que implica el riesgo objetivo de que las personas involucradas lleguen a incurrir en conductas que afecten negativamente determinados intereses públicos o colectivos" ZALAQUETT, José; "Conflictos de intereses: normas y conceptos". Anuario de Derechos Humanos, 2011, p. 181. 
difícil cumplir con su deber justa e imparcialmente. Por cierto la regulación del conflicto de intereses busca preservar la objetividad, imparcialidad idoneidad, pero sobre todo la credibilidad de las decisiones adoptadas por dichos empleados. Por eso como veremos no solo se consuma la situación de conflicto cuando el servidor decide algo en su beneficio, sino aun antes, cuando admite o mantiene aquel interés personal que puede dar la idea razonable aunque así no suceda por lo virtuoso del servidor afectando la credibilidad en la objetividad de la administración. Conforme a su naturaleza de ser un instrumento preventivo de infracciones mayores, para su existencia no es necesaria la consumación del desvío de poder efectivo en un informe, acto, norma o política pública específica, esto es la tangible expresión de la prevalencia del interés ajeno sobre el público en la decisión.

Igualmente es reprobable si otorgo una licencia a un familiar desatendiendo alguna norma legal o si lo hago porque por derecho le corresponde ese acto favorable. Lo reprochable es mi participación en la decisión cuando hay conflicto de intereses.

Este tipo de conflicto de intereses en todos los casos no es corrupción, pero puede dar lugar a comportamientos corruptos. Se ha de subrayar que un conflicto de intereses constituye, objetivamente y por su mismo, una irregularidad grave con independencia de las intenciones de las partes implicadas y que estén actuando de buena o mala fe.

Algunos ejemplos de conflicto de intereses, los podemos encontrar a continuación:

- Si un accionista mayoritario de una empresa de transporte es nombrado Director General de Transporte Terrestre.

- Si un miembro del Comité de Adquisiciones va a evaluar la propuesta de tres empresas, en una de las cuales su hermano tiene acciones.

- Si el Presidente de una empresa estatal en el rubro de hidrocarburos es consultor de empresas privadas en el mismo rubro.

- Si un funcionario de la Superintendencia de Banca y Seguros que tenía a su cargo la supervisión del sistema, renuncia a su cargo y es nombrado Gerente en una empresa bancaria que el supervisaba.

- Si el Presidente del Comité que otorga una concesión en Proinversion, es consultor de las empresas postoras en el proceso.

- Si un inspector laboral desempeña su función en situaciones respecto de los cuales podría tener algún interés directo o indirecto, o cuya posición podrían favorecerlo positiva o negativamente, como si fiscalizara el cumplimiento de las obligaciones laborales de su propio empleador.

\section{IV. ¿Existe una sola clase de conflicto de interés? La tipología de conflictos de intereses}


Existen varios tipos de conflictos de interés que son regulados y reprochados por la ética pública. Desde la perspectiva del momento en el que aparece en interés privado en el servidor público, podemos hablar de conflictos preexistentes al servicio público, concurrentes a éste y subsecuentes o posteriores al servicio público. Por otro lado, desde la perspectiva de las consecuencias del conflicto de intereses, éste puede ser real, potencial o aparente.

\section{Los conflictos preexistentes, concurrentes y subsecuentes a la función pública}

Una cuestión importante para la identificación de los conflictos de interés en el servicio público se refiere a la amplitud temporal de la regulación de los conflictos de interés, de modo que no solo aparezcan durante el ejercicio de la actividad de servicio público sino que sean tomados en cuenta al momento de captar al personal para las entidades y también se impongan como limitación para las actividades posteriores que puedan asumirse al dejar el servicio. La dimensión preexistente y subsecuente del conflicto de interés abordan el problema de las puertas giratorias en la gestión pública (revolving door) por la que quienes aspiran a servir a la función pública son colocados, promovidos o auspiciados por los privados vinculados al quehacer de la agencia y, luego, una vez dejado el servicio público retornan a las mismas empresas u otras, como sus funcionarios, asesores o lobistas.

Con acierto se ha manifestado respecto a estas dos últimas proyecciones del conflicto que "(...) existen argumentos a favor de extender estas disposiciones a situaciones previas y en especial posteriores al empleo público. Tales argumentos sostienen que de no existir tales limitaciones previo al empleo público y al finalizar el mismo se corren dos riesgos. Por una lado, la captura de los cargos públicos por intereses privados si no existen regulaciones preempleo. Por otro lado, si no existen regulaciones pos empleo se corre, además del riesgo antes señalado, que los funcionarios utilicen su cargo público como un trampolín para futuros beneficios en el sector privado. Varios países tienen regulaciones que establecen limitaciones y prohibiciones para los periodos previos y posteriores a los cargos públicos"38

\section{a. Los Conflictos Preexistentes al servicio público}

Este conflicto se refiere, por ejemplo, a los vínculos personales de índole económicos, familiares, societarios, políticos que un ingresante o postulante al servicio tiene o ha tenido recientemente y que se asume como incompatible con el interés público inherente al servicio público al cual se aspira. Propiamente no hay una concurrencia de

38 De Michele 
intereses presentes, sino un conflicto entre el interés privado preexistente y el interés público de la función a la cual se aspira.

De ordinario, este conflicto se expresa en una prohibición razonable para el ejercicio de determinados cargos en la función pública, por lo que el conflicto de interés resulta el fundamento para descalificar a una persona para que ocupe el cargo público.

En nuestro ordenamiento este conflicto es empleado para impedir el ingreso al servicio de cargos directivos en algunas de las entidades públicas tales como para ser Superintendente de Banca y Seguros ${ }^{39}$ si ha tenido participación directa o indirecta en el capital o en el patrimonio de cualquier empresa sujeta a la supervisión de la $\mathrm{Su}$ perintendencia, si es director, asesor, funcionario o empleado de las empresas sujetas al control de la Superintendencia; para ser Contralor General de la Republica si tiene cuentas pendientes de rendición con la Administración Pública o con empresas del Estado, si tienen juicio pendiente con las entidades sujetas a control o si durante los últimos cinco años ha ocupado cargos públicos de responsabilidad directiva ${ }^{40}$ Presidente de la República, Ministro de Estado, Congresista de la República y/o titular de Organismos Autónomos, entidades descentralizadas o de los Gobiernos Regionales y/o Locales; y también lo encontraremos como impedimentos los intereses privados para ser miembros de Consejo Directivo en un organismo regulador de la inversión privada $^{41}$, para integrar el Concejo Directivo, Presidente o miembro del Tribunal de Contrataciones del Estado ${ }^{42}$, para integrar el Consejo Directivo de la SUNASA ${ }^{43}$,

39 Ley General del Sistema Financiero y del Sistema de Seguros y Orgánica de la Superintendencia de Banca y Seguros, Ley No 26702

Artículo $365^{\circ}$.- Impedimentos para ser Superintendente.

Son impedimentos para ser nombrado Superintendente:

1. Tener participación directa o indirecta en el capital o en el patrimonio de cualquier empresa sujeta a la supervisión de la Superintendencia.

2. Ostentar la calidad de director, asesor, funcionario o empleado de las empresas sujetas al control de la Superintendencia.

40 Artículo $29^{\circ}$ - Impedimentos para ser Contralor General

Son impedimentos para ser Contralor General de la República:

e) Tener cuentas pendientes de rendición con la Administración Pública o con empresas que integran la Actividad Empresarial del Estado.

f) Tener juicio pendiente con las entidades sujetas a control, cualquiera sea su naturaleza.

g) Haber sido durante los últimos cinco ańos Presidente de la República, Ministro de Estado, Congresista de la República y/o titular de Organismos Autónomos, entidades descentralizadas o de los Gobiernos Regionales y/o Locales.

41 Ley Marco de los Organismos Reguladores de la Inversión Privada en los Servicios Públicos - LEY No 27332

"Artículo 8.- Incompatibilidades para ser designado como miembro del Consejo Directivo

No pueden ser miembros del Consejo Directivo:

a) Los titulares de más del uno por ciento (1\%) de acciones o participaciones de empresas vinculadas a las actividades materia de competencia de cada Organismo Regulador. Asimismo, los directores, representantes legales o apoderados, empleados, asesores o consultores de tales empresas o entidades;

f) Las personas que prestaron servicios a las entidades reguladas o mantuvieron con ellas relación comercial, laboral o de servicios, bajo cualquier modalidad en el período de un (1) año anterior a su designación, con la única excepción de quienes sólo tuvieron la calidad de usuarios"

42 Impedimentos para ser integrante del Consejo Directivo, Presidente Ejecutivo del OSCE y miembro del Tribunal de Contrataciones del Estado: "no tener participación en personas jurídicas que contraten con el Estado" (LCE art. $61 \mathrm{f})$ y $64 \mathrm{~h}$ )

43 Ley Marco de Aseguramiento Universal en Salud y su Reglamento, Ley No 29344

Artículo $40^{\circ}$.- De los Impedimentos para ser designado miembro Del Consejo Directivo 
entre otros organismos públicos cuyo objeto es la fiscalización, regulación o control de actividades privadas.

\section{b. Los conflictos concurrentes con los intereses del servicio público}

Nos encontramos frente a la figura más conocida de conflictos de intereses que se refieren a los intereses privados de los servidores en ejercicio que confluyen o convergen simultáneamente con el interés público inherente a la función pública actual. En este caso, existe conflicto entre el interés público asignado al cargo que se desempeńa y otro interés privado concurrente o coetáneo a la actividad pública desempeñada.

La regulación nacional aborda este tema de dos maneras: una amplia y general a través del Código de Ética y otra específica y complementaria que identifica por materias y sectores conflictos de interés concurrentes. La primera es por medio del artículo 8 del Código de Ética de la Función Publica cuyo texto es el siguiente:

\section{Artículo 8. - Prohibiciones Éticas de la Función Pública}

El servidor público está prohibido de:

\section{Mantener Intereses de Conflicto}

Mantener relaciones o de aceptar situaciones en cuyo contexto sus intereses personales, laborales, económicos o financieros pudieran estar en conflicto con el cumplimento de los deberes y funciones a su cargo.

Y lo complementa con la definición dada en el Reglamento de la norma por el que se definen "Intereses en Conflicto a aquella situación en la que los intereses personales del empleado público colisionan con el interés público y el ejercicio de sus funciones, entendiéndose que cualquier actuación que realiza dicho empleado público debe estar dirigida a asegurar el interés público y no a favorecer intereses personales o de terceros".

Pero esta normativa vasta y general aparece concretada en diversas normas que abordando problemas específicos de la gestión pública califican situaciones como de conflicto de interés y les dan un tratamiento específico para ello (deber de abstención, impedimento, nulidad del acto, sanción administrativa, etc.). Debe quedar esclarecido que la relación de situaciones calificadas por la normativa y cuyos ejemplos veremos a continuación no son las únicas posibles de existir, porque al amparo de la prohibición general del Código de Ética surgen muchas más, como el amiguismo o partidarismo para el ingreso al servicio o la percepción de financiamiento proveniente de las empresas que son supervisadas, que igualmente están vedadas aunque no tengan una norma tipificadora en particular.

\footnotetext{
Se encuentran impedidos de pertenecer al Consejo Directivo quienes se encuentren bajo alguno de los siguientes supuestos:

1. Tener participación directa o indirecta en el capital o patrimonio de IAFAS, IPRESS, u otra entidad bajo el ámbito de supervisión de la SUNASA o vinculación directa con empresa o entidad que celebre contratos como proveedor excepto que se trate de entidades del Estado.
} 
Una breve relación de situaciones calificadas normativamente como de conflicto de intereses concurrentes son las siguientes:

- Informar, conocer o resolver un procedimiento estando vinculado por razón de parentesco con cualquiera de los administrados o con sus representantes, mandatarios, con los administradores de sus empresas, o con quienes les presten servicios; si ha intervenido antes como asesor, perito o testigo en el mismo procedimiento, o si como autoridad hubiere manifestado previamente su parecer sobre el mismo, de modo que pudiera entenderse que se ha pronunciado sobre el asunto; si personalmente, o bien su cónyuge o algún pariente dentro del cuarto grado de consanguinidad o segundo de afinidad, tuviere interés en el asunto de que se trate o en otra semejante, cuya resolución pueda influir en la situación de aquél; si tuviere amistad íntima, enemistad manifiesta con cualquiera de los administrados intervinientes en el procedimiento, o si tuviere o hubiese tenido en los últimos dos ańos, relación de servicio o de subordinación con cualquiera de los administrados o terceros directamente interesados en el asunto, o si tuviera en proyecto una concertación de negocios con alguna de las partes, aun cuando no se concrete posteriormente ${ }^{44}$.

- Participar como postor, interesado o contratista, directa o indirectamente o incluso adquiere cualquier derecho real por legado, sobre los bienes del organismo al cual se sirve e incluso los bienes confiados a la administración, custodia o intervención ${ }^{45}$.

- Prestar servicios, aceptar representaciones remuneradas o participar en el directorio de empresas o instituciones privadas comprendidas en el ámbito específico de su función pública, aun cuando haya transcurrido un año posterior al cese o a la culminación de los servicios prestados bajo cualquier modalidad contractual ${ }^{46}$.

- Adquirir directa o indirectamente acciones o participaciones de empresas privadas comprendidas en el ámbito de su función, de sus subsidiarias o las que pudieran tener vinculación económica, celebrar contratos civiles o mercantiles con estas; intervenir como abogados, apoderados, asesores, patrocinadores, peritos o árbitros de particulares en los procesos que tengan pendientes con la misma repartición del Estado en la cual prestan sus servicios ${ }^{47}$.

- Ejercer la facultad de nombramiento y contratación de personal o ejercer injerencia, directa o indirecta, en el proceso de selección o contratación de personas, respecto de parientes y convivientes ${ }^{48}$.

44 Ley del Procedimiento Administrativo General, Art. 88.

45 Artículo 1366 del Código Civil:

46 Ley No. 27588, Ley que establece prohibiciones e incompatibilidades de funcionarios y servidores públicos, así como de las personas que prestan servicios al Estado bajo cualquier modalidad; art. 2.

47 Ley No. 27588, Ley que establece prohibiciones e incompatibilidades de funcionarios y servidores públicos, así como de las personas que prestan servicios al Estado bajo cualquier modalidad; art. 2.

48 Ley No. 30057. Ley del Servicio Civil. 
- Los integrantes de Tribunales o instancias encargadas de resolver conflictos en sede administrativa, no pueden mantener relaciones con respecto de las empresas y entidades que hubieran participado en causas tramitadas ante dichas reparticiones, durante el tiempo en que dichas personas ejercieron el $\operatorname{cargo}^{49}$.

- En el ámbito municipal, constituye conflicto de interés concurrente si los regidores, los alcaldes, los servidores, empleados y funcionarios municipales contratan, participan en licitaciones de obras o servicios públicos municipales o adquieren directamente o por interpósita persona sus bienes ${ }^{50}$.

- Realizar actos de gestión de intereses a fin de orientar alguna decisión publica, establecimiento de políticas o toma de decisiones de cualquier naturaleza que tengan una significación económica, social o política de carácter individual o colectivo, o que afecten intereses en los diversos sectores de la sociedad en favor de intereses privados ${ }^{51}$.

\section{c. Los conflictos de intereses subsecuentes al interés del servicio público}

La Convención de las Naciones Unidas contra la Corrupción (art. 12) recomienda entre las medidas para evitar la corrupción en el sector privado, la de:

“5. Prevenir los conflictos de intereses, imponiendo restricciones apropiadas, durante un periodo razonable, a las actividades profesionales de ex funcionarios públicos o a la contratación de funcionarios públicos en el sector privado tras su renuncia o jubilación cuando estas actividades o esa contratación estén directamente relacionada con las funciones desempeñadas supervisadas por esos funcionarios públicos durante su permanencia en el cargo".

Nos encontramos frente a aquellos supuestos en que intereses privados incompatibles con el servicio público surgen o se transparenten en un ex servidor público con posterioridad al cese del servicio público. Hay un conflicto de intereses entre el interés público ya atendido durante el desempeño del cargo y el interés privado posterior que se pretende desempeñar a la salida del cargo. La idea que subyace en este caso, es evitar mediante impedimentos temporales o absolutos que los servidores busquen, propicien o acepten generar vínculos posteriores a su gestión pública en base a conflicto de intereses o con aprovechamiento de elementos conocidos en su desempeño público que también es de interés público mantenerse reservados. Por ello, la preocupación aparece cuando el ex servidor genera un vínculo privado cercano y sensible con la posición que tenía cuando era servidor público.

49 D.S. No. 019-2002-PCM, Reglamento de la Ley No. 27588, Artículo 2.

50 Ley Orgánica de Municipalidades (Ley No. 27972), arts. 22 y 63.

51 Ley No. 28024, Ley que regula la gestión de intereses en la administración pública. 
Estos conflictos se revelan como restricciones sobre las alternativas de ofertas de trabajo u ocupaciones que puede desempeñar un servidor saliente de la gestión pública, a fin de evitar que deliberadamente o a instancia de los privados realice -o de la apariencia que se realizan-un uso ilícito de conexiones e influencias profesionales sobre excolegas, subordinados o que haya torcido con interés privado sus últimas decisiones en el servicio público. De esta manera, la regulación de los conflictos de intereses subsecuentes quiere evitar la realización o apariencia que:

- Los servidores públicos en funciones modifiquen su conducta para mejorar sus perspectivas de empleo luego de la separación: "Dicha conducta puede incluir el favorecimiento de interés privados por encima de las responsabilidad pública; funcionarios que se comportan de manera suave en sus responsabilidades oficiales para mejorar intereses personales en su carrera; un individuo que actúa con parcialidad identificándose sobre manera con los eventuales futuros intereses de empleadores; o, soborno claro, cuando un funcionario solicita empleo luego de su separación, a cambio del desempeño corrupto de sus responsabilidades" ${ }^{2}$.

- Los ex servidores usen de manera inapropiada información confidencial del gobierno adquirida durante el curso de sus funciones oficiales, para obtener beneficio personal. Ej. Información sensible y protegida de competidores de otras empresas.

- Los ex servidores busquen influenciar a otros servidores, sus anteriores colegas o a subordinados para que actúen con parcialidad, buscando influir en su trabajo o garantizando favores.

A dicho efecto, los ordenamientos acogen periodos de carencia para poder realizar o asumir determinadas actividades privadas vinculadas con sus actos de gestión durante su desempeńo como servidor público.

Nuestra legislación contempla como conflictos de interés sobrevivientes a la gestión, los siguientes supuestos generales aplicables a todos servidores públicos por un periodo de un año posterior a su cese en el servicio ${ }^{53}$ :

- Representar o asistir a un administrado en algún procedimiento respecto del cual tuvo algún grado de participación durante su actividad en la entidad.

- Asesorar a cualquier administrado en algún asunto que estaba pendiente de decisión durante su relación con la entidad.

- Realizar cualquier contrato, de modo directo o indirecto, con algún administrado apersonado a un procedimiento resuelto con su participación.

- Realizar actos de gestión de intereses a fin de orientar alguna decisión publica, establecimiento de políticas o toma de decisiones de cualquier naturaleza que tengan una significación económica, social o política de carácter individual o

52 TRANSPARENCIA, p. 301.

53 LPAG, Artículo $241^{\circ}$. 
colectivo, o que afecten intereses en los diversos sectores de la sociedad en favor de intereses privados

\section{d. Los conflictos reales, potenciales, aparentes y tolerados}

\section{(i) El conflicto de interés real}

Existe cuando el interés privado del servidor en efecto interfiere con sus obligaciones públicas, afectando la independencia de criterio profesional y se plasma dictando una decisión, parecer o tramitación atendiendo su interés personal. Es la consumación del conflicto del interés mediante alguna decisión u omisión concreta, constitutiva de desvío de poder y, por ende, genera para su infractor las consecuencias de responsabilidad consiguientes, de orden penal, civil o administrativa, previstas por el ordenamiento. Ej. Si el empleado decide el ingreso a la entidad de un familiar suyo.

En este caso, generalmente el ordenamiento jurídico da una calificación propia y adicional al conflicto de interés, como por ejemplo, nepotismo, tráfico de influencia, concusión, etc.

\section{(ii) El Conflicto de interés aparente}

Es cuando sin haber llegado a perpetrarse el aprovechamiento de poder por el servidor, la concurrencia de intereses en que se encuentra el servidor da ocasión a que las otras personas que observan la situación razonablemente llegan a la percepción que dicho interés ejerce una influencia indebida en el responsable público, aun cuando, de hecho, no lo ejerza. Aquí hay la concurrencia de intereses pero no llega a producirse un ilícito adicional al conflicto concreto por la rectitud del empleado, debido a la ausencia de la oportunidad o por cualquier circunstancia similar. Es el caso por ejemplo, de un servidor del Ministerio de Energía y Minas a cargo de temas mineros, quien posee acciones en una empresa minera.

En esa medida, se afirma que "Un conflicto aparente de intereses se da cuando hay un interés personal implicado que podría hacer pensar razonablemente a los ciudadanos que dicho interés ejerce una influencia indebida en el responsable público, aun cuando, de hecho, no la ejerza o, incluso, cuando de hecho no exista tal influencia" ${ }^{34}$.

Aquí no existe conflicto real, ni desvió de poder en la decisión, pero la imagen y la reputación de la autoridad así como la confianza de la ciudadanía en la justicia e imparcialidad de los procedimientos queda en duda, por lo que debe evitarse indudablemente.

Como afirma Transparencia Internacional:

"los conflicto de intereses percibidos cuando son tomadas las decisiones

54 Villoria (2006), p. 298. 
correctas, pueden ser tan dañinos para la reputación de la organización y erosionar la confianza pública, como un conflicto de intereses realmente existente"s5.

\section{(iii) El conflicto intereses potencial}

Sucede cuando el responsable público tiene un interés privado o personal que podría en el futuro causarle un conflicto con el interés público que debe resguardar aunque no exista ahora ese conflicto. Ej. Si un familiar trabaja en la misma entidad pero sin dependencia directa actualmente o si un familiar de un Gerente de Administración de una entidad, constituye una empresa con la finalidad de proveer productos a otras entidades públicas. Es una situación potencial que debe ser justamente objeto de tratamiento preventivo por la regulación mediante mecanismos idóneos.

Los conflictos de intereses aparentes y potenciales pueden ser tan dañinos para el prestigio y credibilidad de la administración, como un conflicto de intereses realmente existente, aun cuando se hayan tomado las decisiones correctas.

Lo que se busca es evitar que un potencial conflicto de interés se convierta en un real conflicto a través de diversos mecanismos. En el promedio de los servidores públicos el solo conflicto potencial provoca una antesala de dilema moral que psicológicamente le será difícil resolver hacia el interés público llegado el caso. Aun cuando podríamos suponer que contamos con servidores públicos competentes, independientes, capacitados y altruistas que adoptaran siempre decisiones racionales y objetivas hacia el interés público, es contraproducente tener ese interés privado en posible colisión siguiendo el orden natural de las cosas.

Es bueno tener presente que según ha establecido la psicología experimental56 existen sesgos inconscientes y no intencionados en los seres humanos que hacen particularmente difícil y muchas veces imposible atender los estándares éticos deseables, introduciendo distorsiones en el momento de decidir. Por ejemplo:

55 Merino y Lozano, p. 294

56 Argandoña (2004), p. 9 y ss. Al respecto recomendamos leer Bazerman y Tenbrunsel (2011). En este interesante trabajo se informa que las personas muchas veces actúan en sentido contrario a lo que le exigen sus propios valores éticos debido a sesgos conductuales humanos, tales como: el favoritismo intragrupal (tendencia a favorecer a personas con las que se sientes más cercanos o similares solo por el deseo de ser bien amigo, familiar, asociado, etc.), el prejuicio ordinario (discriminación natural hacia personas que se sienten alejadas del perfil que uno mismo desea), la exageración del crédito o egocentrismo que hace incrementar los aspectos positivos y minimizar el conflicto o justificarlo por una buena causa), la ética delimitada (tendencia a excluir de nuestras decisiones información pertinente y colocar elementos arbitrarios), la difuminacion ética (que permite que cuando se pronostica una decisión se haga desde estándares y razonamientos éticos, pero cuando pasamos a la acción lo hacemos impelidos por emociones o pasiones instantáneas que descartan el juicio ético -el querer antes que el deber-), además de pasar por alto las conductas no éticas, mediante la ceguera motivada (tendencia a pasar por alto la conducta reprochable de un tercero porque me beneficia ignorarla), la ceguera indirecta (no detectar la ausencia de escrúpulos cuando el actitud antiética se hace por medio de otros) y la pendiente resbaladiza (aceptamos una pequeńa infracción inicial, y luego poco a poco vamos permitiendo otras más graves) y la valoración utilitarista de privilegiar los fines y resultados en vez de la conducta ética que es el medio. 
- Los agentes tienden a verse a sí mismos como personas morales, competentes y merecedoras de reconocimiento; en comparación con los demás, se ven como más honestos, confiables, justos y objetivos;

- Los agentes, inconscientemente, excluyen cuando analizan la situación del conflicto, aquella información que podría contradecir la visión que tienen sobre sí mismos y no son conscientes de esa exclusión;

- Los agentes se ven afectados -la más de las veces inconscientemente- por los roles que asumen, de manera que la preferencia por un resultado concreto acaba justificando su sentido de justicia en la interpretación de las situaciones, tienden a sesgar su noción de lo que es justo de modo que resultan beneficiados personalmente por la decisión

- Los agentes tienden a ser selectivos a la hora de evaluar la situación, aceptando más fácilmente la que apoya la conclusión que desean sacar y valorándola de forma acrítica, entre otras.

Por ello, cuando se abordan los conflictos de intereses potenciales, es válido concluir que "Como consecuencia de todo ello, la definición básica aquí usada asume que, si una persona razonable, conociendo todos los datos relevantes, pudiera concluir que los interés privados o personales del responsable publico estarían en condiciones de influir impropiamente en su conducta o toma de decisiones, o en la imagen del Estado, dicha situación debe evitarse" 57 .

\section{(iv) Conflicto de interés inevitable o tolerado}

Es conveniente diferenciar el verdadero conflicto del falso conflicto de interés, cuando si bien concurren en la misma persona ambos intereses, el interés privado no corresponde a un aprovechamiento o ventaja sino una condición natural e igualitaria para una generalidad de ciudadanos. Por ejemplo, la concurrencia en un empleado público la función de supervisor de bancos y mantener cuentas bancarias o tomar un préstamo en una empresa financiera del Sector, o ser empleado de OSINERGMIN y tener suministro eléctrico con una empresa regulada.

\section{El conflicto de interés como limitación constitucional proporcional a derechos fundamentales}

La regulación del conflicto de interés se traduce, por lo general en prohibiciones, impedimento, inhabilidades para ejercer alguna actividad humana. Pueden servir para impedir el acceso a un cargo, para prohibir ejercer -de manera parcial o total, y permanente o transitoria- una actividad privada concurrente o posterior al ejercicio

57 Villoria (2006), p. 299. 
del servicio público, impedir ser contratista del Estado, entre otros. También puede implicar tener que renunciar o transferir algún patrimonio lícitamente obtenido, soportar la carga de revelar ese patrimonio o las fuentes de ingresos. En concreto se limitan derechos como el del ejercicio de la profesión, la libertad de empresa, la libertad de trabajo, entre otras. Ello es evidente, pero la pregunta que nos debemos hacer, ¿es ello constitucionalmente aceptable? ¿Si es así, porque?

Al respecto resulta clásica la STC 178/1989 del Tribunal Constitucional Español mediante la cual resolvió la cuestión planteada por un grupo de parlamentarios del Congreso contra los artículos de la Ley 53/1984 sobre Incompatibilidades del personal al servicio de las Administración Publicas. Precisamente la demanda afirmaba la inconstitucionalidad de algunas reglas de incompatibilidad por afectar la libertad de trabajo de los servidores públicos.

Ante ello el Tribunal Constitucional desestimó la demanda afirmando que no supone "una vulneración, restricción o limitación inconstitucional alguna al derecho al trabajo" sino que más bien que "el derecho al trabajo no es vulnerado o menoscabado por el hecho de que para su ejercicio -en concreto, en el ámbito de la función pública entendida en sentido amplio- se impongan por el legislador determinados requisitos o limitaciones para garantizar la consecución de determinados objetivos fijados en la propia Constitución"

La sentencia concretamente desarrollo su planteamiento de la siguiente forma:

“(...) Que el establecimiento de dicho sistema supone, evidentemente limitaciones subjetivas para los empleados públicos, tanto para compatibilizar dos o más puestos en la Administración Publica como para hacer compatibles el ejercicio de la función pública o, en general, la ocupación de un puesto de trabajo en el sector público con el ejercicio de una actividad profesional privada, es innegable. Pero de ahí no puede concluirse, en modo alguno, que la Ley que establezca ese sistema y, en concreto, la Ley No. 53/1984 vulnera el derecho constitucional al trabajo. Y, ello, porque el derecho al trabajo constitucionalmente protegido no garantiza de modo alguno el derecho a que dicho trabajo se desarrolló en determinadas condiciones, con ausencia de determinadas limitaciones, sino que garantiza, simplemente, que el legislador, en el ámbito de la función pública, no va a imponer requisitos o condiciones que no respondan a los intereses públicos a los que con objetividad, ha de servir, como impone el artículo 103.1 de la Constitución, la organización -la administración pública- en la que se encuadran los servidores o empleados públicos. Si ello es así, si la finalidad a que responde el sistema de incompatibilidades en el mejor atendimiento de los intereses públicos, no puede decirse $-\mathrm{y}$ no puede decirse tampoco en este caso- que la norma que lo establece vulnera el 
derecho al trabajo, que se sitúa, por lo que hemos dicho, en otro plano diferente. De ahí que el legislador, pueda regular, especialmente cuando se trata de trabajo desempeñado al servicio de las Administración Publicas, no solo el modo de acceso al mismo tema ajeno a la cuestión que aquí se plantea- sino también las condiciones y requisitos para el desempeño del mismo, incluidas las incompatibilidades con el desarrollo de actividades profesionales o laborales al margen de la considerada por el legislador. Bien entendido, por lo demás, que el sistema de incompatibilidades regulado en la Ley No. 53/1984 no vulnera tampoco, como implícitamente pretenden en algunos pasajes de su demanda los recurrentes, la libertad de elección de profesión y de oficio consagrada, al igual que el derecho al trabajo en el artículo 35.1. de la Carta Fundamental.

La ley impugnada no impide a nadie llevar a cabo esa elección, como tampoco la de desempeñar la profesión y oficio elegidos libremente. Lo que impide o condiciona, según los casos, es que los empleados públicos, mientras estén al servicio de una Administración Publica desempeñen otra actividad profesional o laboral distinta a la propia de su empleo público. Lo cual es evidentemente, algo muy diferente" 58 .

En una línea muy similar, nuestro Tribunal Constitucional ha tenido ocasión de pronunciarse reiteradamente ${ }^{59}$ sobre la admisibilidad constitucional de las restricciones a la libertad del ejercicio profesional impuestas legalmente a los empleados públicos para hacer compatible otros valores constitucionales y el principio de buen gobierno dentro del Estado de derecho. Enfrentado al aparente dilema el Tribunal Constitucional afirmó ${ }^{60}$ desestimando el argumento que le fue planteado por un servidor público acerca de la posibilidad de ejercer fuera del horario de trabajo, la profesión de abogado, que una limitación como impuesta por la ley para ejercer actividades privadas, aun fuera del horario del trabajo, es constitucional y cumple con los criterios de razonabilidad y proporcionalidad para alcanzar otros fines valiosos que la propia Constitución señala:

“7. Conforme se observa en la Resolución N. 30, de fecha 16 de mayo de 2002, el emplazado sustentó la decisión de no permitir que el recurrente ejerciera como abogado amparándose en el ar-

58 STC 178/1989 de 2 de noviembre. Recurso de inconstitucionalidad 272/1985,. BOE No. 290, Suplemento lunes 4 de diciembre de 1989 .

59 SSTTCC recaídas en los EXP. No. 2235-2004-AA/TC y 2234-2004-AA ambos recursos extraordinarios promovidos por don Grimaldo S. Chong Vasquez contra el Poder Judicial por presuntas violaciones a sus derechos al trabajo, al libre desarrollo de la personalidad, a la libre contratación y a la igualdad ante la ley por haber rechazado su participación como abogado en dos procesos judiciales como representación de empresas financieras debido a que desempeńaba el cargo de ejecutor coactivo en la Municipalidad Provincial de Paita. Cabe señalar que conforme al artículo 7 inciso 2) de la Ley No. 26979, de Ejecución Coactiva dicho cargo es de dedicación exclusiva.

60 EXP. N. ${ }^{\circ} 2235-2004-A A / T C$, LIMA, Grimaldo Saturnino Chong Vásquez. 
tículo $7^{\circ}$, inciso 2 de la Ley N.o 26979. Dicho precepto dispone que:

“Tanto el Ejecutor como el Auxiliar ingresarán como funcionarios de la Entidad a la cual representan y ejercerán su cargo a tiempo completo y dedicación exclusiva”

9. (...) El problema a esclarecer, pues, es (...) si la disposición legislativa en virtud de la cual se restringió un derecho del actor satisface las exigencias de los principios de razonabilidad y proporcionalidad, a los que antes se ha hecho referencia.

10. Aunque el legislador no lo haya afirmado expresamente, cuestión que, por otra parte, no tiene por qué hacerlo cuando legisla, al Tribunal Constitucional no le cabe ninguna duda de que detrás de la disposición limitativa del derecho a ejercer libremente la profesión de quienes tienen la condición de Ejecutores Coactivos se encuentra el principio constitucional de buena administración, implícitamente constitucionalizado en el Capítulo IV del Título II de la Constitución. En lo que aquí interesa poner de relieve, dicho principio quiere poner en evidencia no sólo que los órganos, funcionarios y trabajadores públicos sirven y protegen al interés general, pues "están al servicio de la Nación" (artículo 39 de la Constitución), sino, además, que dicho servicio a la Nación ha de realizarse de modo transparente. Transparencia que exige que el Estado prevea todos los medios organizacionales, procedimentales y legales destinados a evitar que determinados funcionarios y trabajadores públicos, con poder de decisión o influencia en la toma de decisiones trascendentales para la buena marcha de la administración, puedan encontrarse restringidos en mayor medida que otros servidores públicos en el ejercicio de determinados derechos fundamentales. Es el caso, por ejemplo, de quienes ejercen el cargo de Congresistas, para quienes, de acuerdo con el tercer párrafo del artículo $92^{\circ}$ de la Constitución, su cargo es incompatible con la condición de gerente, apoderado, representante, mandatario, abogado, accionista mayoritario o miembro del Directorio de empresas que tienen con el Estado contratos de obras, de suministro o de aprovisionamiento o que administran rentas públicas o prestan servicios públicos. Pero también es el de los Jueces, quienes tampoco pueden actuar como abogados, salvo casos muy excepcionales contemplados en la Ley Orgánica del Poder Judicial.

11. El cargo de Ejecutor Coactivo perteneciente también a esa esfera de la función pública y, en virtud de ello, por efecto del principio de transparencia, está limitado en el ejercicio de algunos 
derechos fundamentales $y$, en particular, del libre desempeño de la profesión de abogado. Tales restricciones se derivan de la propia naturaleza de la función que desempeña el Ejecutor Coactivo, puesto que se trata de un funcionario que es responsable de llevar adelante el procedimiento administrativo destinado al cumplimiento de las acreencias impagas a favor de una entidad de la administración pública.

En esa medida, la necesidad de evitar colusiones ilegales, favorecimientos indebidos, u otros de naturaleza análoga, que pongan en peligro los deberes del ejercicio del cargo para con el órgano de la administración, la comunidad y el Estado, tornan razonable una medida como la contemplada en el artículo $7^{\circ}$, inciso 2 de la Ley N.o 26979.

12. Por último, este Tribunal tampoco considera que la medida limitativa del derecho al libre ejercicio de la profesión no satisfaga las exigencias del principio de proporcionalidad, pues, como se ha visto, se trata de una medida: a) idónea para alcanzar el fin constitucionalmente legítimo; b) necesaria, porque no se ha acreditado otro medio, menos aflictivo, para conseguir el mismo fin, ni este Tribunal considera que la opción adoptada por el legislador importe un sacrificio excesivo o innecesario, sobre el derecho limitado; y, c) los perjuicios que genera sobre el derecho afectado no son superiores al interés que se persigue satisfacer".

En una posterior Sentencia igualmente se ratificó en señalar que “(...) el derecho al libre ejercicio de la profesión, como todo derecho fundamental, puede ser restringido para satisfacer fines constitucionalmente valiosos (...). De este modo, en el caso de la profesión de abogado, el derecho al libre ejercicio de la profesión se encuentra limitado cuando se desempeña la función pública de Ejecutor Coactivo, funcionario que es responsable de llevar adelante el procedimiento administrativo destinado al cumplimiento de las acreencias impagas a favor de una entidad de la administración pública. En esa medida, tal como se refiere en la precitada sentencia, la necesidad de evitar colusiones ilegales, favorecimientos indebidos, u otros de naturaleza análoga, que pongan en peligro los deberes del ejercicio del cargo para con el órgano de la administración, la comunidad y el Estado, hacen que la limitación establecida en el artículo $7^{\circ}$, inciso 2 de la Ley N. 26979 resulte proporcional con el fin constitucional que se pretende proteger, como es en este caso el principio constitucional de buena administración implícitamente constitucionalizado en el Capítulo IV del Título I de la Constitución”. 


\section{VI. ¿Cómo identifica un servidor público si incurre en conflicto de intereses?}

La identificación del conflicto de intereses suele ser realizado por medio de los instrumentos de control ciudadano, el control político o el control gubernamental. Pero ellos, por lo general, detectan el estado de conflicto cuando este ya se ha consumado y no cuando es potencial o aparente. Por ello, el más oportuno mecanismo, es que sea detectado preventivamente por el propio servidor público el conflicto aparente y el potencial.

En esa línea de pensamiento, dado que el empleado público es la persona que mejor conoce si se encuentra en una situación de conflicto de intereses, se debe reconocer que cada servidor público tiene la responsabilidad personal de:

- Estar permanentemente atento para prevenir e identificar cualquier relación o circunstancia que puede conducir a cualquier potencial o aparente conflicto de interés. Así cuando va a adquirir acciones de una empresa, establecer una relación comercial en una sociedad privada, etc.

- Tomar medidas para evitar tal Conflicto, a través de advertir la situación de conflicto o cuando ello se ha producido, informar de ello a las instancias competentes.

- Siendo el conflicto de interés una condición necesaria y razonable para el ejercicio correcto de funciones públicas debe ser consciente que no debe participar en una actividad u operación o adquirir cualquier posición o tarea, ya sea remunerado o no, que sea incompatible con la performance apropiada de sus deberes como funcionario público ${ }^{61}$.

- Cuando no está claro si una actividad es compatible, debe buscar el asesoramiento de su superior, personal especializado u órganos competencia en materia de ética pública para adoptar decisiones informadas o apropiadas.

- Revelar a las instancias competentes o a sus superiores cualquier situación de conflicto tan pronto como él o ella sea consciente de ello, y adoptar la decisión legalmente admisible para retirarse de la situación de conflicto o despojarse de la causa de dicho estado ${ }^{62}$.

${ }_{61}$ "Código Iberoamericano de Buen Gobierno", Respaldado por la XVI Cumbre Iberoamericana, Uruguay, noviembre de 2006. http://old.clad.org/documentos/declaraciones/codigoiber.pdf/view

17. Se abstendrán de toda actividad privada que pueda constituir un conflicto de intereses con su cargo público, entendiéndose que existe conflicto cuando los altos cargos intervienen en las decisiones relacionadas con asuntos en los que real o aparentemente, de acuerdo a criterios razonables, confluyan a la vez, o puedan confluir en el futuro, intereses de su puesto público e intereses privados propios, de familiares directos, o intereses compartidos con terceras personas.

En similares términos nuestra regulación califica la prohibición funcional de "intervenir en asuntos donde sus intereses personales, laborales, económicos o financieros pudieran estar en conflicto con el cumplimiento de los deberes y funciones a su cargo" (art.157 literal b) D.S. No. 040-2014-PCM, Reglamento General de la Ley No. 30057 .

62 Artículo 13.3. "Código Modelo de Conducta para los agentes públicos", Recomendación No. R (2000) 10, aprobada por el Consejo de Ministros del Consejo de Europa. 
Algunas de las preguntas claves que el empleado puede formularse para dilucidar si se encuentra en un conflicto de intereses son los siguientes ${ }^{63}$ :

- ¿Qué pasaría si se invierten las posiciones: si yo fuera uno de los tantos que está solicitando un trabajo o una promoción y uno de los que debe tomar dicha decisión estuviera en la posición que yo me encuentro? ¿Pensaría que el proceso fue justo?

- ¿Puedo yo, un familiar, un amigo o un asociado, ganar o perder financieramente a causa de la decisión o acción de la organización al respecto?

- ¿Puedo yo, un familiar, un amigo o un asociado, ganar o perder mi/nuestra reputación ante una decisión o acción de la organización?

- ¿ ¿He contribuido de alguna forma a título personal al asunto sobre el que se habrá de decidir o actuar?

- ¿Soy miembro de alguna organización, club u organización profesional, o tengo vínculos o afiliaciones particulares con organizaciones o individuos que ganen o pierdan como resultado de la consideración de la organización sobre el asunto?

- ¿Podría haber en el futuro beneficios personales para mí, los cuales podrían generar duda sobre mi objetividad?

- ¿Si participo en la evaluación o toma decisiones, me preocuparía si mis colegas y el público llegaran a conocer mi asociación o conexión?

- ¿Una persona justa y razonable notaria que fui influenciado por un interés personal al desempeñar mis responsabilidades públicas?

\section{El tratamiento de los conflictos de interés (medidas preventivas y represivas). La necesidad de equilibrio y de eficacia en el diseño de medidas contra los conflictos de intereses y los riesgos de diseño}

Un problema tan complejo y multifacético como es el de los conflictos de intereses no puede ser objeto de una sola alternativa. Es más, resulta improbable que puedan evitarse todos los conflictos de interés con las medidas que se adopten, pero es necesario intentarlo de manera sostenida como una estrategia preventiva sobre la corrupción. Es verdad que "ninguna regulación puede evitar que los intereses de los servidores públicos desaparezcan o tan siquiera medir en que forma el juicio de un funcionario ha sido afectado; por eso las regulaciones más bien han evolucionado hacia evitar o prohibir

$63 \quad$ La Hora de la Transparencia, p. 295. 
el desarrollo de ciertos tipos de intereses en general para siquiera impedir que se entre en una relación donde exista la tentación de sucumbir al conflicto" ${ }^{\text {"4 }}$.

Este fenómeno amerita una combinación de mecanismos de distinta envergadura y con diversas perspectivas. Así se postula que a la medidas penales de tipificación de los ilícitos basados en los conflictos de interés consumados, sean acompañados de medidas administrativas represivas para inconductas de menor entidad, pero también instrumentos preventivos de tipo prohibitivo o impeditivos como mecanismos positivos, eficaces y prácticos que atendiendo a la presunción que la mayoría de servidores públicos son movidos por la honradez permitan solucionar la situación a quienes "viéndose envuelto en conflicto de intereses, constructivamente pretendieren desembarazarse".

Ante ello, un panorama general de la regulación de conflicto de intereses se refleja en una suma de medidas preventivas y represivas de los conflictos de interés. Las medidas preventivas más usuales son la regulación, en diversos grados, de prohibiciones, Incompatibilidades, impedimentos o inhabilidades para ejercer actividades privadas antes, durante o posteriores al ejercicio de la función pública (cuyo grado máximo es la dedicación a exclusiva al cargo público); la reasignación de funciones: traslado del funcionario a otro cargo, la obligación de la renuncia del servidor, las declaraciones juradas de bienes y rentas que permiten transparentar relaciones comerciales e ingresos con particulares antes y durante el ejercicio de la función, la separación del cargo o la abstención de casos específicos, la habilitación de la recusación que pueda ser ejercida por los ciudadanos, el abandono compulsivo de los intereses privados previa a la asunción del cargo, tales como la transferencia de patrimonio o constitución de fideicomisos $\operatorname{ciegos}^{65}$, la transferencia del interés privado hacia la organización administrativa o hacia la colectividad (ej. Declaración de fuentes de ingresos, de parentesco y de intereses, realización de consultas preventivas a la oficina competente si considera dudosa o incierta la existencia de conflicto en el caso concreto) y para ello crear instancias especializadas en capacitar, orientar, reflexionar y calificar circunstancias de conflicto de interés, como Comités de Ética ${ }^{66}$.

Por otro lado, las medidas represivas frente a los conflictos de intereses abordan el conflicto de interés ya producido y puede recaer el reproche sobre el servidor público (responsabilidad administrativa o disciplinaria, política o incluso penal) ${ }^{67}$ y sobre el

64 Arellano Gault y Zamudio Gonzalez (2009), p. 149.

65 Un panorama completo de la funcionalidad y aplicabilidad de los fideicomisos ciego como instrumentos para prevenir conflicto de intereses en las autoridades con patrimonios relevantes podemos encontrarlo en: "Normativa sobre conflicto de intereses y legislación sobre fideicomiso ciego". Documento de Trabajo No.9, Agosto, 2009. Chile Transparente, Capitulo Chileno de Transparencia Internacional.

66 Las medidas de transparencia o revelación son importantes porque tienden a prevenir futuros conflictos y permitir visibilizar riesgos de conflictos, pero no eliminan verdaderamente la fuente de conflicto sino solo la pone de manifiesto y ello demanda labor de fiscalización concurrente o mecanismos sociales de seguimiento, ni tampoco excluye sino que más bien hace necesario que cuando concurra el conflicto aplique otras medidas como por ejemplo, la abstención de la función o cargo.

67 En el derecho peruano la responsabilidad por incurrir en conflictos de interés se encuentra inconvenientemente y anti técnicamente superpuesta por instrumentos de responsabilidad disciplinaria (Ley de Servicio Civil), responsabilidad por transgresión de las normas de Código de Ética, responsabilidad política que conduce a 
acto administrativo o decisión que se ha producido como influencia del interés privado que constituye desvío de poder por transgredir la finalidad publica del acto.

El sentido común mínimo nos indica que la regulación debe tener una visión de conjunto del problema y no una visión agregada que sume inarmónicamente instrumentos de punición, represión y prohibición. Ello con el objetivo de evitar dos riesgos extremos en esta regulación: el riesgo del perfeccionismo: exigir a los empleados estándares ideales de virtuosismo y el riesgo de la ineficiencia. Por el primero, el legislador debe ser consciente que una regulación apropiada no puede partir de concebir un servidor público plenamente altruista, desprendido del interés personal dispuesto a sacrificarse incluso a su familia, sin aspiraciones futuras, que no es el ciudadano promedio que ocupa funciones públicas. Como ello es así, el énfasis debe estar en mecanismos preventivos. Pero del otro lado, existe el riesgo que por exceso de medidas preventivas y represivas, la administración se prive de contar con personal competente y especializado, desaliente a quien ya ocupan los cargos públicos y promueva, sin proponérselo, el éxodo de servidores públicos al sector privado. No obstante ninguno de estos riesgos puede conducir a crear excepciones particulares o en función de las personas a las reglas éticas, bajo apariencia de eficiencia.

Por ello, se ha afirmado que es importante diferenciar las diversas medidas de regulación de los conflictos de interés en "regulación sustantiva" y en "regulación procedimental"68. La primera se dirige a conseguir un resultado determinado inmediato: prohibiciones, sanciones, incompatibilidades, periodos de carencia, exclusiones, entre otras La regulación procedimental o soluciones de proceso, por el contrario, se centran en el proceso a seguir para evitar la aparición de conflicto o facilitar su resolución, por ejemplo, creación de comités de ética, regulación de la abstención, declaraciones previas de intereses e ingresos. Ahora bien, enjuiciando ambas clases de medidas es patente la superioridad de las ultimas sobre las primeras, dada que si bien las medidas de regulación sustantiva son fáciles de elaborar y ser cómodas para las autoridades o legislador, suelen ser ineficientes porque "no pueden considerar la variedad de relaciones posibles entre el agente y el principal; es probable, por tanto, que desanimen conductas legítimas, o que, por el contrario, sean insuficientes a la hora de evitar las conductas indeseables. Además, los agentes pueden internalizar las penas (que pasaran a formar parte de su análisis de costes y beneficios de rendirse a un conflicto de intereses); crean incertidumbre ex ante; son difíciles de aplicación ex post; pueden acentuar los efectos del conflicto de intereses haciendo más importante evitar el castigo que actuar según el interés del principal, etc." ${ }^{69}$.

Una regulación con prohibiciones y restricciones extensas o periodos de carencia puede hacer inútil es esfuerzo por captar personal especializado, porque por lo general esa especialidad se adquiere en las empresas privadas del sector. Así sucedería si por ejem-

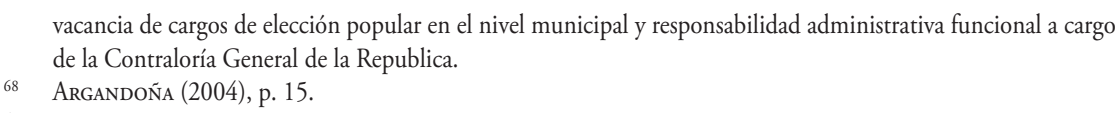


plo, se estableciere que para laborar en una determinada entidad pública no podrían postular quienes han prestado servicios a empresas del sector, o si estableciera que no pueden ser postores a ninguna entidad en contrataciones con el Estado a quienes tuvieren como uno de sus representantes a un familiar de una autoridad pública aunque ella no tuviera ninguna influencia en la entidad a la cual se postula.

El equilibrio y la directa conexión entre la regla impeditiva y el conflicto de interés nos indican que "Existen una serie de consideraciones que deben tenerse en cuenta a la hora de escoger las pautas de comportamiento ético en la función pública. Si se restringe demasiado el acceso a la función pública (con un sistema sobredimensionado de carencias ex ante y ex post, por ejemplo) se corre el riesgo de no poder contar con ciudadanos experimentados en ciertas áreas con escases de personal capacitado, con lo que se perjudicaría el nivel de servidores públicos. También es necesario atender el riesgo de que los decisores públicos se sientan paralizados ante el marco regulatorio demasiado engorroso, con lo que se vería afectada la dinámica de la gestión pública. Estas preocupaciones son genuinas y cualquier sistema de reglas que aspire a una mínima racionalidad y eficacia debe atenderlas"70.

\section{Conclusiones}

1. El conflicto de interés es una institución jurídica con fundamento indudablemente en la ética, que es aplicable a diversas situaciones en las que en una persona concurren dos lealtades distintas de difícil convivencia para la toma de decisiones objetiva: una basada en su propio interés personal (económico, profesional, laboral, amical, partidario, corporativo, etc.) y otra, juzgada de mayor relevancia, que le exige actuar de modo altruista conforme a los intereses del otro y actuar de modo que inspire y acreciente la confianza de esa otra persona.

2. En el ámbito administrativo, el conflicto de intereses es cualificado porque el sujeto en quien concurren ambos intereses en controversia es quien ejerce funciones públicas y tiene por vocación de principio anteponer el bienestar del público a sus intereses privados y tomar decisiones sólo con arreglo al interés general. Como esta exigencia también se extiende en algunos casos a algunos colaboradores de la administración quienes no obstante ser particulares, como contratistas y concesionarios, les resultan exigibles deberes de lealtad hacia el interés público, el régimen de conflicto de interés también les resulta aplicables.

3. El objetivo de regular apropiadamente los conflictos de interés en la gestión pública radica en que su acaecimiento constituye la base indispensable para la comisión de otras prácticas indebidas agravadas, tales como: la captura del estado por los intereses privados, el nepotismo, la captura de la Administración por partidos políticos, el tráfico

70 Alegre, p. 5. http://www.cdh.uchile.cl/media/publicaciones/pdf/5/267.pdf 
de influencias, uso indebido de información privilegiada, concusión, corrupción, la institucionalización de la puerta giratoria en el acceso y salida de servidores, etc. Por ello, su prevención es fundamental para la prevención de la corrupción, la recuperación de la legitimidad democrática y la ejemplaridad del quienes nos gobiernan.

4. Los conflictos de interés que se pueden identificar con motivo del ejercicio de la función pública pueden ser de diversos tipos: de unos lados preexistentes, concurrentes y subsecuentes al ejercicio de la función pública y del otro lado, los conflictos reales, potenciales, aparentes y tolerados.

5. La institución del conflicto de interés lleva en sí mismo, implícitamente, una serie de deberes para los servidores públicos, tales como: estar permanentemente atento para prevenir e identificar cualquier relación o circunstancia que puede conducir a cualquier potencial o aparente conflicto de interés, tomar prestamente medidas para evitar tal conflicto, ser consciente que no debe participar deliberadamente en una actividad u operación o adquirir cualquier posición o tarea, ya sea remunerado o no, que sea incompatible con la performance apropiada de sus deberes como servidor, buscar el asesoramiento de su superior, del personal especializado o de órganos competentes en materia de ética pública para adoptar decisiones informadas o apropiadas, revelar a las instancias competentes o a sus superiores cualquier situación de conflicto tan pronto como él o ella sea consciente de ello, y adoptar la decisión legalmente admisible para retirarse de la situación de conflicto o despojarse de la causa de dicho estado.

6. La regulación del conflicto de interés implica una ponderación de valores constitucionales: por un lado el deber predominante de los servidores públicos de ejercer sus funciones al servicio de la Nación y el ejercicio, por el otro, sus libertades de empresa, de trabajo y de ejercicio de la profesión, etc. Es el legislador quien aplicando criterios de razonabilidad y proporcionalidad establece que situaciones se consideran como conflicto de intereses y la medida preventiva y/o represiva aplicable a cada caso, restringiendo en diversa medida las antedichas libertades. Por ello, todo tratamiento jurídico a los conflictos de interés (medidas preventivas y represivas) debe tener en cuenta la necesidad de alcanzar un equilibrio y eficacia en su diseño para evitar la ilusión del perfeccionismo conductista a través de las normas puramente aspiracionales y el riesgo de la incorporar ineficiencia a la gestión pública mediante sobre regulación, negar la posibilidad de captar personal especializado o promover la fuga de capital humano competente al sector privado.

\section{Referencias Bibliográficas}

ALEGRE, Marco: "Informe final, Regulación de pautas de comportamiento ético y conflicto de intereses en la Argentina”; p. 5. http://www.cdh.uchile.cl/media/ publicaciones/pdf/5/267.pdf 
ARELLANO GAULT, David; ZAMUDIO GONZALEZ, Laura (2009): “Dilemas organizacionales e institucionales de las regulación es para contener los conflictos de interés en una democracia; una aproximación comparativa entre Canadá, EUA y México", en: Revista Convergencia, Vol. 16, Núm. 49, enero-abril 2009, UNAM, México.

ARGANDOÑA, Antonio (2004): "Conflicto de intereses: el punto de vista ético". Documento de Investigación No. 552. Marzo, 2004. Publicado por la Cátedra de Economía y Ética. Universidad de Navarra. IESE Business School. http://www. iese.edu/research/pdfs/DI-0552.pdf

BAZERMAN, Max H. y TENBRUNSEL, Ann E. (2011): "Blind Spots: Why We Fail to Do What's Right and What to Do about It". Princeton University Press, Princeton, New Jersey.

CARBONELL PORRAS, Eloísa (1999): "Los Órganos Colegiados: organización, funcionamiento, procedimiento y régimen jurídico de sus actos”. Centro de Estudios Políticos y Constitucionales. Serie Cuadernos y Debates No. 83, Madrid.

DE MICHELLE, Roberto (2004): "Los conflictos de intereses en el Sector Publico". Acción Ciudadana, proyecto Alianza por la Transparencia - Fortalecimiento de los Órganos de Control., Guatemala. http://archive.transparency.org/regional_pages/americas/publicaciones/sourcebook_esp/hora_transparencia\#sthash. XDRM3AT9.dpuf.

MERINO, Valeria y LOZANO; Juan (compiladores); "La hora de la Transparencia en América Latina Elaborado por Transparencia Internacional para América Latina y el Caribe TILAC".

MINISTERIO DE ADMINISTRACIONES PÚBLICAS, INSTITUTO NACIONAL DE ADMINISTRACIÓN PÚBLICA. "Normas de Conducta para la Vida Pública. El Informe Nolan” Serie Documentos INAP.

OCDE (2004): "Managing conflict of interest in the public service". Paris.

OLSON, Robert G (1874): "The morality of self-interest", Henry Sidgwick; The Methods of Ethics. London, 1874; James Rachels; The Elements of Moral Philosophy",

RAILE, Eric; "Manejo de los Conflictos de Interés en las Américas: una revisión comparativa”.

RODRIGUEZ-ARANA MUÑOZ, Jaime (1993): Principios de Ética Publica ¿Corrupción o servicio?. Editorial Montecorvo S.A., Madrid.

SAINZ MORENO, F. (1983): "Ejercicio privado de funciones públicas", RAP No. 100-02 (1983).

SAVATER, Fernando (1988): "Ética, política, ciudadanía", Editorial Grijalbo, México.

TRANSPARENCIA INTERNACIONAL (2009): "Normativa sobre conflicto de intereses y legislación sobre fideicomiso ciego". Documento de Trabajo No.9, Agosto, 2009. Chile Transparente, Capitulo Chileno de Transparencia Internacional. 
VILLORIA, Manuel (2006): "Políticas y prácticas para gestionar los conflictos de interés en Europa: una visión comparada”; Revista do Servicio Público. Brasilia 57 (3): Julio/Setiembre 2006, p. 298.

WEBER, Max (1997): ¿Qué es la Burocracia?” Libros Taurus, Argentina. 